\title{
ACE2 activation protects against cognitive decline and reduces amyloid pathology in the Tg2576 mouse model of Alzheimer's disease
}

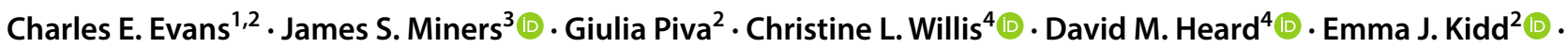 \\ Mark A. Good ${ }^{1}$ (1) Patrick G. Kehoe ${ }^{3}$ (])
}

Received: 29 August 2019 / Revised: 16 October 2019 / Accepted: 8 November 2019 / Published online: 25 January 2020

(c) The Author(s) 2020

\begin{abstract}
Mid-life hypertension and cerebrovascular dysfunction are associated with increased risk of later life dementia, including Alzheimer's disease (AD). The classical renin-angiotensin system (cRAS), a physiological regulator of blood pressure, functions independently within the brain and is overactive in AD. cRAS-targeting anti-hypertensive drugs are associated with reduced incidence of $\mathrm{AD}$, delayed onset of cognitive decline, and reduced levels of $\mathrm{A} \beta$ and tau in both animal models and human pathological studies. cRAS activity is moderated by a downstream regulatory RAS pathway (rRAS), which is underactive in $\mathrm{AD}$ and is strongly associated with pathological hallmarks in human $\mathrm{AD}$, and cognitive decline in animal models of CNS disease. We now show that enhancement of brain ACE2 activity, a major effector of rRAS, by intraperitoneal administration of diminazene aceturate (DIZE), an established activator of ACE2, lowered hippocampal A $\beta$ and restored cognition in mid-aged (13-14-month-old) symptomatic Tg2576 mice. We confirmed that the protective effects of DIZE were directly mediated through ACE2 and were associated with reduced hippocampal soluble $\mathrm{A} \beta_{42}$ and IL1- $\beta$ levels. DIZE restored hippocampal MasR levels in conjunction with increased NMDA NR2B and downstream ERK signalling expression in hippocampal synaptosomes from Tg2576 mice. Chronic (10 weeks) administration of DIZE to pre-symptomatic 9-10-month-old Tg2576 mice, and acute (10 days) treatment in cognitively impaired 12-13-month-old mice, prevented the development of cognitive impairment. Together these data demonstrate that ACE2 enhancement protects against and reverses amyloid-related hippocampal pathology and cognitive impairment in a preclinical model of AD.
\end{abstract}

Keywords Alzheimer's disease $\cdot$ Renin-angiotensin system $\cdot$ ACE2 $\cdot$ MasR $\cdot$ DIZE $\cdot$ Angiotensin-(1-7)

Joint authorship: Charles E. Evans and James S. Miners.

Electronic supplementary material The online version of this article (https://doi.org/10.1007/s00401-019-02098-6) contains supplementary material, which is available to authorized users.

James S. Miners

scott.miners@bristol.ac.uk

$\triangle$ Patrick G. Kehoe

Patrick.Kehoe@bristol.ac.uk

1 School of Psychology, Cardiff University, Cardiff CF10 3AT, UK

2 School of Pharmacy and Pharmaceutical Sciences, Cardiff University, Cardiff CF10 3NB, UK

3 Dementia Research Group, Translational Health Sciences, Bristol Medical School, University of Bristol, Level 1 Learning and Research, Southmead Hospital, Bristol BS10 5NB, UK

4 School of Chemistry, University of Bristol, Cantock's Close, Bristol BS8 1TS, UK

\section{Introduction}

Overactivity of the classical renin-angiotensin system (cRAS) within the brain has been implicated in the pathogenesis of Alzheimer's disease (AD) (reviewed by [1, 2]). Elevated ACE1 activity and higher levels of Ang-II and the angiotensin-II type 1 receptor (AT1R) have been reported in human AD brain tissue [3-6]. Evidence from large epidemiological and clinical studies indicate that some cRAS-targeting anti-hypertensives, including ACE1 inhibitors (ACE-Is) and AT1R receptor blockers (ARBs), reduce the incidence of $A D$ [7-9], and can prolong the conversion to MCI and delay the onset of dementia [10-12]. Clinical use of anti-hypertensives is associated with improved tau and A $\beta$ indexes in CSF and autopsied brain tissue $[11,13,14]$. Insights from animal models indicate that the protective effects of ACE-Is and ARBS are associated with anti-inflammatory and anti-oxidative stress 
Table 1 Numbers of mice used in each experiment. The age at which mice commenced and finished behavioural assessment and were culled is shown

Cohort 1 (30 Day DIZE administration)

\begin{tabular}{lllllll}
\hline WT Vehicle & Tg2576 Vehicle & Tg2576 DIZE & - & Total & Age at Start & Age at End \\
\hline 12 & 11 & 9 & - & 32 & 13.5 months & 15 months \\
\hline
\end{tabular}

Cohort 2 (30 Day DIZE and DIZE+C16 administration)

\begin{tabular}{lllllll}
\hline WT Vehicle & Tg2576 Vehicle & Tg2576 DIZE & Tg2576 DIZE+C16 & Total & Age at Start & Age at End \\
\hline 21 & 12 & 13 & 11 & 57 & 13.5 months & 15 months \\
\hline
\end{tabular}

Cohort 3 (30 Day DIZE administration; Synaptosome Analysis

\begin{tabular}{lllllll}
\hline WT Vehicle & Tg2576 Vehicle & WT DIZE & Tg2576 DIZ & Total & Age at Start & Age at End \\
\hline 7 & 7 & 7 & 7 & 28 & 13 months & 15 months \\
\hline
\end{tabular}

Cohort 4 (10-Week and 10-Day administration)

\begin{tabular}{lllllll}
\hline WT Vehicle & Tg2576 Vehicle & Tg2576 DIZE (10-week) & Tg2576 DIZE (10-day) & Total & Age at Start & Age at End \\
\hline 20 & 16 & 11 & 17 & 64 & 9 months & 12 months \\
\hline
\end{tabular}

mechanisms, in addition to lowering blood pressure and improving cerebral blood flow [15-17]. Clinical trials are currently underway to determine if cRAS-targeting antihypertensives will have a beneficial effect in patients with $\mathrm{AD}[18,19]$.

Activity of the cRAS is counterbalanced by downstream regulatory RAS (rRAS) pathways [20, 21], which appear to be the dominant RAS pathways in the brain [22, 23]. Enzymes such as ACE2 and aminopeptidases-A and -N convert Ang-II (and Ang-III) into smaller bioactive fragments, most commonly Ang-1-7 and Ang-IV, reducing Ang-II associated cRAS signalling via AT1R. Recent findings show reduced CNS activity in the rRAS pathway and that induction of ACE2, or Ang-(1-7) activation of MasR signalling, is neuroprotective against ischaemic stroke and neurogenic hypertension in experimental animal models of CNS injury [24, 25]. ACE2 overexpression is associated with reduced cRAS signalling, including reduced ACE1 activity, AngII level and AT1R expression [26-29] and reduced oxidative stress and neuro inflammation. In a recent comparative study, rRAS activation outperformed a prototype cRAS blocker in reducing oxidative and inflammatory responses in an ischemia/reperfusion mouse model of stroke [30]. Activation of downstream rRAS receptors, such as MasR, insulin-regulated aminopeptidase (IRAP) and c-MET, which are primarily expressed in the hippocampus [31], all induce long-term potentiation (LTP) and knockout of MasR disrupts object recognition memory in rodents [32, 33] and reviewed by [34]. Collectively these data suggest that rRAS activation offers protection against many of the pathological disease processes associated with cRAS activation that are characteristic in AD but may in addition directly benefit normal cognition, through promoting synaptic plasticity processes linked to memory.

We have previously shown that there is dysregulation of endogenous rRAS activity in postmortem confirmed AD brain tissue, which is strongly associated with cRAS overactivation and disease pathology (A $\beta$ and Tau) $[35,36]$. Specifically, ACE2 activity, predominantly involved in the conversion of Ang-II to Ang-(1-7) [37, 38], was reduced by almost $50 \%$ in $\mathrm{AD}$ cases, which was significantly related to $\mathrm{A} \beta$ and Tau levels [35]. In an ovariectomised D-galactose rodent model of ageing and dementia, enhancement of ACE2 activity by administration of DIZE reduced brain A $\beta$ pathology and improved cognitive performance [39]. We now present the first data of the impact of ACE2 enhancement in an established transgenic APP mouse model, Tg2576 mice, in which the timing and onset of $\mathrm{A} \beta$ pathology and behavioural abnormalities have been well characterised and recognised to model abnormalities in human AD. This study tested the hypotheses that enhancement of ACE2, using an established ACE2 activator (DIZE), will reduce A $\beta$-related pathology and restore cognitive function in symptomatic aged $\mathrm{Tg} 2576$ mice and prevent the onset of cognitive decline when administered to pre-symptomatic (younger) Tg2576 mice.

\section{Materials and methods}

\section{Animals}

A total of 182 male mice were used in this study across four separate cohorts (see Table 1). All WTs and Tg2576 mice within each individual cohort were from the same 
litters to act as appropriate littermate controls. Mice were individually housed due to their aggressive behaviour, as previously reported [40, 41]. Tg2576 mice expressing the human $A P P^{695 S w e}$ mutation were maintained on a hybrid $\mathrm{C} 57 \mathrm{Bl} / 6 \times \mathrm{SJL}$ background [42]. Mice were housed on a 12-h light-dark cycle. Testing occurred during the light period (08:00-19:00). Mice were allowed ad libitum access to food and water throughout the duration of the experiment. All experiments were conducted in compliance with the UK Home Office under the Animal Scientific Procedures Act (1986) and EU regulations.

\section{Drugs}

Diminazene aceturate (DIZE) was purchased from SantaCruz Biotechnology (CAS 908-54-3). DIZE was freshly prepared daily in $0.9 \%$ sterile saline to a concentration of $50 \mathrm{mg} / \mathrm{ml}$. DIZE was administered to $\mathrm{Tg} 2576$ mice at $15 \mathrm{mg} / \mathrm{kg} /$ day by intraperitoneal (i.p.) injection using a BD MicroFine ${ }^{\mathrm{TM}}$ 0.5-ml insulin syringe. All other mice received equivalent volumes of vehicle (saline) injections. This dose was based on several previous studies showing that the optimal dose of DIZE in inducing ACE2 activity was $15 \mathrm{mg} / \mathrm{kg} /$ day $[39,43,44]$ and a preliminary study of our own across a range of DIZE concentrations by IP that confirmed previous findings (data not shown).

A competitive ACE2 antagonist, based on the structure of a commercially available compound, C16 (MLN4760, Merck Millipore) was synthesised according to reported procedures [45], and purified by reverse phase flash chromatography. Purity and identity were confirmed by ${ }^{1} \mathrm{H}$ and ${ }^{13} \mathrm{C}$ NMR spectroscopy, polarimetry, high-resolution mass spectrometry and HPLC. The compound data were in good accordance with the literature and the inhibitor performed similar to the commercial inhibitor when tested in vitro using recombinant mouse ACE2 (R\&D systems) (data not shown). The ACE2 inhibitor was co-administered with DIZE in relevant experiments, in an identical vehicle as DIZE, at $25 \mathrm{mg} / \mathrm{kg} /$ day, which was the dose most consistently used in previous C16 studies [46, 47].

\section{Experimental design}

In Experiment 1, we investigated whether DIZE influenced cognitive performance and $A \beta$-related pathology in male 13-15-month-old Tg2576 mice. An outline of the experimental design is shown in Fig. 1a. Mice from cohort 1 consisted of three groups: WT vehicle $(n=13), \mathrm{Tg} 2576$ vehicle $(n=11)$ and Tg2576 DIZE $(n=11)$. Prior to group allocation, all mice were tested on the object-in-place (OiP) task (as described below) to establish a baseline of cognitive performance and to ensure that the Tg2576 groups had a comparable level of performance prior to drug administration. Following group allocation, all mice were weighed and six mice/group were used to assess mean arterial blood pressure (MABP) and heart rate (HR) at baseline (see also below). A 30-day DIZE/vehicle treatment period then commenced. Mice received daily i.p. injections in the morning and were rested for at least $1 \mathrm{~h}$ before any physiological/ behavioural testing was performed. Mice were weighed and MABP and HR measurements were recorded weekly in the sub-groups of mice until the end of the treatment period. Behavioural assessment was again conducted starting with habituation on day 23 of drug treatment followed by the OiP task on day 28 and day 30 of treatment. Immediately following behavioural assessment at day 30 , the mice were culled by cervical dislocation and the left and right hippocampi and cortices were dissected and snap frozen in liquid nitrogen and stored at $-80{ }^{\circ} \mathrm{C}$ until processed for downstream biochemical and pathological assessment. A total of three mice in cohort 1 died during the Experiment 1 -one WT vehicle and two from the $\mathrm{Tg} 2576$ DIZE group (one on day 2 of administration and the second on day 29). Therefore, the final $\mathrm{n}$ for the WT vehicle group was $n=12$, the $\operatorname{Tg} 2576$ vehicle group remained at $n=11$ and the Tg2576 DIZE group was $n=9$.

In Experiment 2, we aimed to (1) replicate our findings from Experiment 1 in a larger independent cohort (cohort 2) and (2) determine if the observed protective effects of DIZE were specific to ACE2 enhancement. The experimental design used identical dosing and behavioural testing methods as outlined for Experiment 1 (see Fig. 1a). However, in this experiment, we included an additional group of mice that were co-administered DIZE and C16 (an ACE2 inhibitor) to test the hypothesis that enhanced ACE2 activity was required for the protective effects of DIZE. A total of four mice died in cohort 2 (two mice administered DIZE and two administered DIZE + C16). Final group numbers in cohort 2 were, therefore, as follows: WT vehicle $(n=22), \operatorname{Tg} 2576$ vehicle $(n=11), \mathrm{Tg} 2576$ DIZE $(n=12), \mathrm{Tg} 2576 \mathrm{DIZE}+\mathrm{C} 16$ ( $n=11)$. Cohorts 1 (Experiment 1) and 2 (Experiment 2) were used for discovery and replication studies, respectively, to test and verify the behavioural changes independently but brain tissue was collected and combined from both cohorts, given the identical experimental dosages and design, to allow for meaningful statistically powered biochemical assessment of changes in ACE2, A $\beta$, cytokines, and markers of astrocyte, microglial and vascular function.

In Experiment 3, we studied a separate cohort of mice (cohort 3 ) consisting of four groups: WT vehicle $(n=7)$, WT DIZE $(n=7), \operatorname{Tg} 2576$ vehicle $(n=7)$ and Tg2576 DIZE $(n=7)$ (all 13-15 months old). The addition of WT DIZE group was designed to assess if DIZE affected WT mice behaviour and biochemistry in the same way as $\operatorname{Tg} 2576$ mice. The experimental procedure replicated that of 


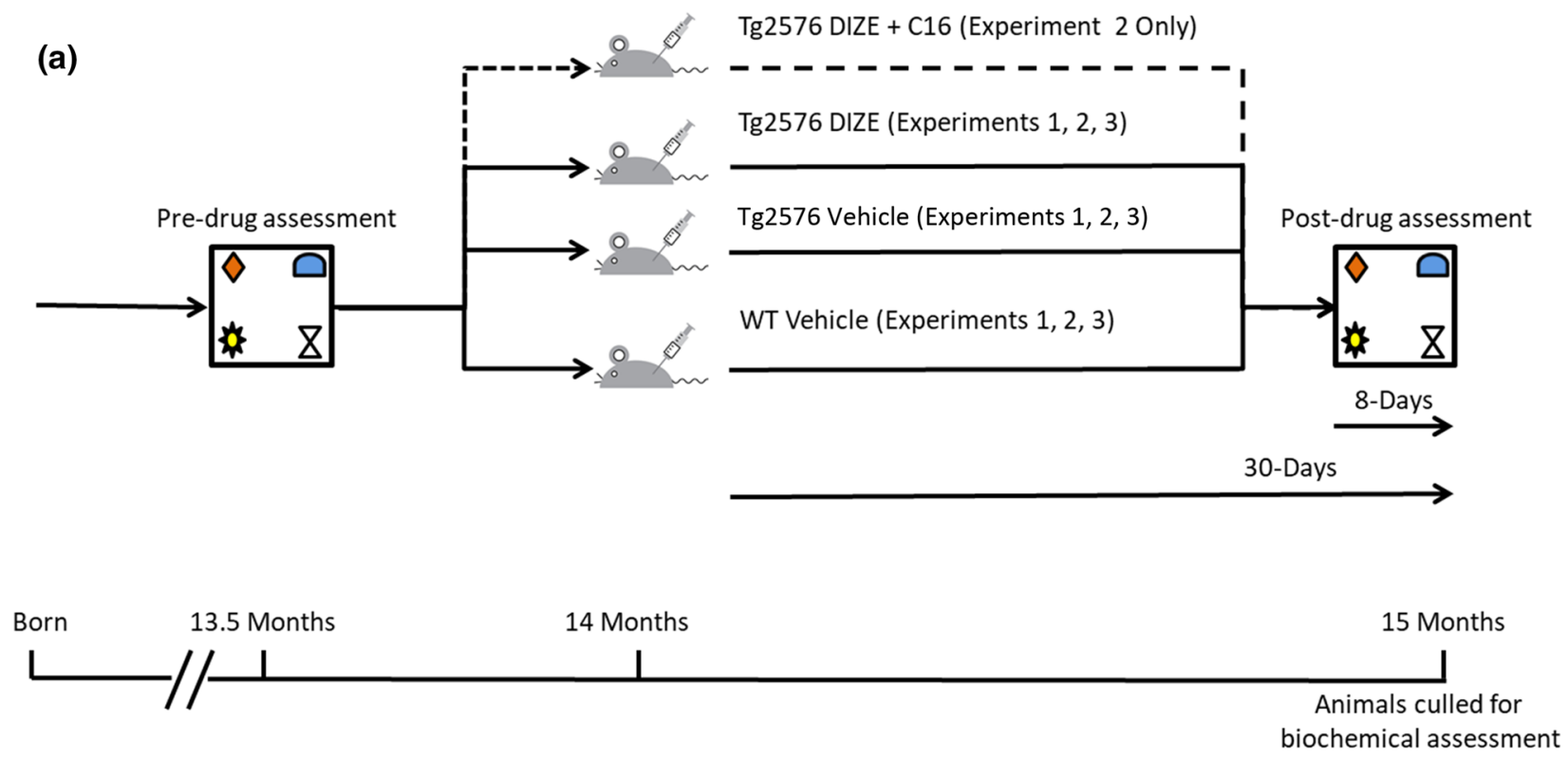

(b)

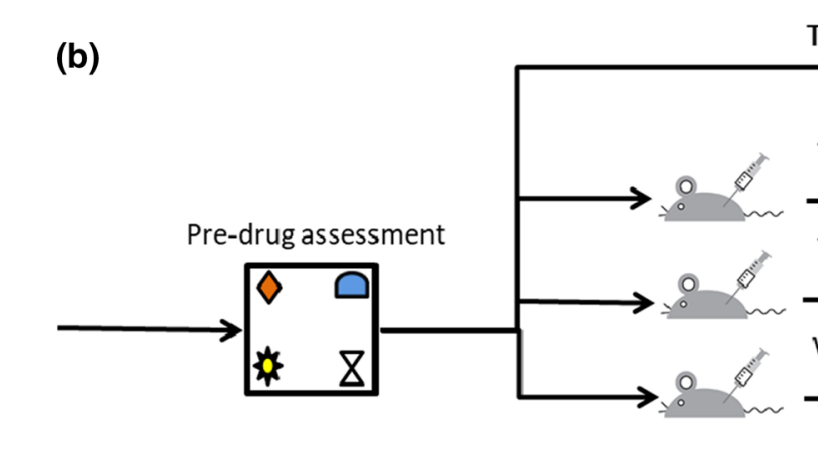

$\operatorname{Tg} 2576$ DIZE (Acute)

Tg2576 Vehicle

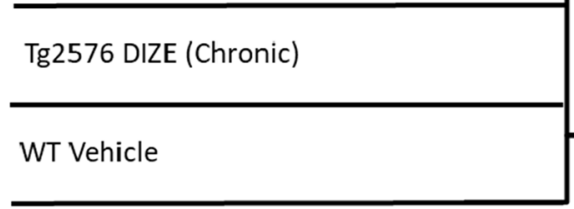

Post-drug assessment
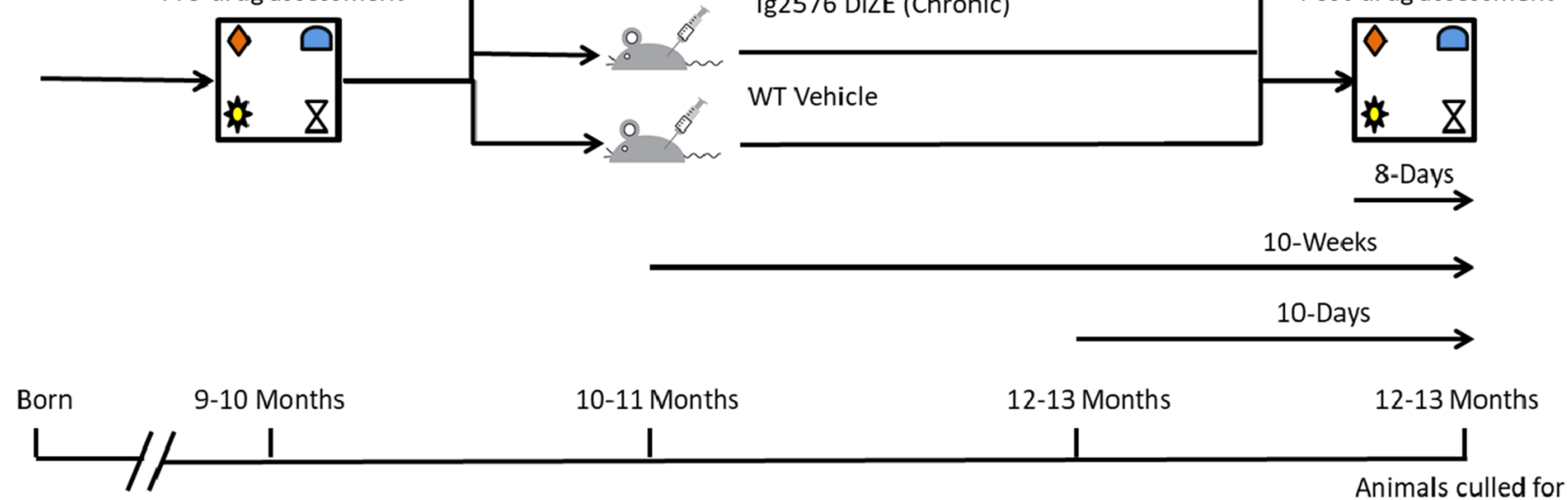

10-Weeks

10-Days

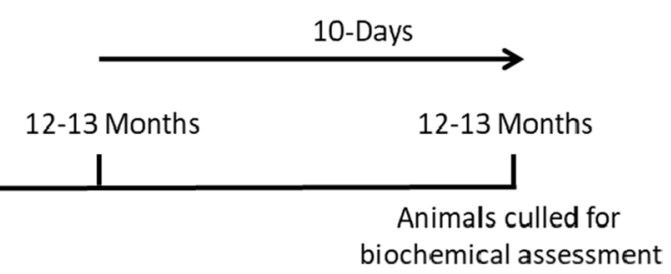

Fig. 1 Schematic representation of the experimental design in a for Experiments 1, 2 and 3 and $\mathbf{b}$ for Experiment 4. a Male mice between 13 and 14 months of age were subject to pre-drug assessment in the object-in-place (OiP)-associative recognition memory task to establish a baseline measurement. Mice were then randomly assigned into groups to ensure that there was no significant difference in behaviour prior to treatment. All WT mice were administered vehicle (saline) only. In Experiment 1, Tg2576 mice were administered either vehicle (saline) or DIZE ( $15 \mathrm{mg} / \mathrm{kg} /$ day) for 30 days. In Experiment 2, a third $\mathrm{Tg} 2576$ group was added that was administered DIZE + C16 $(25 \mathrm{mg} /$ $\mathrm{kg}$ /day) for 30 days. In Experiment 3, both WT and Tg2576 groups were administered vehicle or DIZE. In each experiment, on day 23 of treatment, post-drug assessment commenced with habituation and testing was performed on days 28 and 30. All mice were culled and brains were dissected on day 30 immediately following post-testing and underwent pathological and biochemical assessment. b Mice underwent pre-drug assessment at 9-10 months of age and all mice were found to be asymptomatic. The mice were then divided into four groups: WT vehicle, $\mathrm{Tg} 2576$ vehicle, $\mathrm{Tg} 2576$ DIZE (chronic) and Tg2576 DIZE (acute). Tg2576 groups were allocated based on OiP performance so that all groups showed comparable levels of contact time and DR score performance. All groups except Tg2576 DIZE acute commenced IP DIZE treatment $(15 \mathrm{mg} / \mathrm{kg} / \mathrm{day})$ or vehicle for 10 weeks. At 8 days prior to the final two test days at 12-13 months of age, DIZE acute mice received drug treatment daily for 10 days ( $15 \mathrm{mg} / \mathrm{kg} /$ day). Tg2576 mice had previously been shown to be cognitively impaired at 12-13 months of age in Experiments 1 and 2 . Mice across all four groups were re-tested at 12-13 months of age. At the end of the study, after all mice had undergone OiP testing, they were culled immediately and underwent pathological and biochemical assessments 
Experiments 1 and 2. Upon completion of this study, mice brains were either snap frozen for biochemical assessment or processed for IHC and IF analyses.

In Experiment 4, we used a 4th group of mice (cohort 4) to investigate if long-term (10 weeks) DIZE administration (Tg-DIZE chronic) could protect against the development of $\mathrm{A} \beta$ pathology and cognitive impairment when administered to pre-symptomatic younger mice aged 9-10 months. To validate and extend our observations on the beneficial effects of DIZE in aged (symptomatic) Tg2576 mice, we compared the chronic treated (10 weeks) condition with a group that received DIZE acutely for 10 days (Tg-DIZE acute) at $12-13$ months of age $(n=17)$ immediately prior to behavioural testing and tissue collection. The experimental procedure is summarised in Fig. 1b. We studied WT vehicle $(n=20), \operatorname{Tg} 2576$ vehicle $(n=16)$ and Tg-DIZE chronic $(n=11)$ or Tg-DIZE $(n=17)$.

\section{Behavioural assessment}

All mice were tested on the OiP task as previously described $[48,49]$. A detailed description of the OiP task is presented in Supplementary Fig. 1, online resource. Briefly, prior to testing associative recognition memory, animals were habituated to the arena. Mice were allowed to explore the arena freely for $10 \mathrm{~min}$ on day 1 and day 2. Mice were then further habituated for two consecutive days to the arena containing four different objects for $10 \mathrm{~min}$ each day. Each object was approximately $15 \mathrm{~cm}$ from the walls of the arena and $25 \mathrm{~cm}$ apart from each other. This arrangement remained constant throughout the study. A different set of objects was used each day and across both time points tested. No sets of objects were re-used during habituation or testing. Each mouse received two rounds of behavioural testing; each test was separated by $48 \mathrm{~h}$. The group of objects used and specific pair of objects that underwent a location switch and their order across days were counterbalanced within and between groups.

Time spent exploring the objects was recorded in both sample and test phases. Object exploration was defined according to the methods described previously by Ennaceur and Delacour (1988). In brief, object contact was defined as when an animal was within a $2 \mathrm{~cm}$ radius of the object and directly facing, sniffing, gnawing, but not climbing or sitting on, the objects. A discrimination ratio (DR) was used to provide an index of the mouse's discrimination performance in the test phase that was independent of individual differences in object contact times; this was calculated as the time spent exploring objects in novel locations/the time spent exploring all objects. All reported contact times and DR scores were averaged across the two trials. We mitigated against the potential effects of repeat testing in our study by counterbalancing across object sets and switching the location of objects within and between groups. All objects were cleaned before each phase of testing to reduce the use of odour cues introduced from handling the objects.

\section{Blood pressure measurement}

Our aim was to use a dose of DIZE that influenced ACE2 activity but did not change blood pressure. The effect of DIZE (15 mg/kg/day) on MABP and HR was, therefore, assessed at weekly intervals over the entire course of the study in Experiment 1. Measurements were taken prior to DIZE treatment to determine a baseline MABP and then at weekly intervals until the end of the study. Six mice from each treatment group were habituated to the apparatus (Harvard Apparatus) and used throughout the study. To habituate animals for MABP and HR recordings, each mouse was given a 15-min trial/day for 4 days. Mice were placed in a mouse holder (Part no. 76-0184) underneath a heating unit (Part no.76-0178) in a dark room. The tail cuff and pulse transducer (Part no. 76-0432) were placed around the mouse's tail and inflated 7-8 times/session. Following habituation, each mouse was placed in the holding unit and given 2-3 min to adapt to the dark room and warmth from the heating device, after which the tail cuff was inflated and MABP and HR was recorded from the blood pressure recording unit (Part no. 76-0173). Three recordings (that were averaged) were taken per mouse. Mice were then removed from the holding unit and returned to home-cages, after which the holding units were wiped clean with $70 \%$ ethanol wipes and allowed to dry thoroughly between mice, to prevent stress that may have been caused from residual scents from other males.

\section{Biochemical measurements of markers of disease pathology}

Immediately following behavioural testing, mice were culled by cervical dislocation and their brains were removed and dissected. In Experiments 1, 2 and 4, both hemispheres were dissected into cortex, hippocampus and frontal cortex and snap frozen at $-80{ }^{\circ} \mathrm{C}$ until protein extraction as previously described [51]. In Experiment 3, the left hemisphere was dissected as above, snap frozen, and used for synaptosome extraction (see below). The contralateral hemisphere was fixed in 4\% PFA in $0.1 \mathrm{M}$ PBS for $12 \mathrm{~h}$ before being transferred to $25 \%$ sucrose in PBS for $48 \mathrm{~h}$. Brains were then sliced using a vibratome and stored in cryoprotectant as previously described [52].

\section{Synaptosome extraction}

Synaptosome extractions were performed using Syn-PERTM synaptic protein extraction reagent (ThermoFisher, UK). 
Western blotting was performed using standard methods as described previously [51]. Briefly, after protein quantification, $20 \mu \mathrm{g}$ protein/sample was resolved on either a 10 or $7.5 \%$ polyacrylamide gel and detected with the relevant antibody (NR2B, pY1472-NR2B (Millipore), GluA1, pSer845 GluA1, PSD95 (Abcam), total ERK, phospho-ERK (Cell Signalling Technologies), NR1 (BD Biosciences), Total Tau (DAKO), PHF1 (p-Tau Ser396/404; a generous gift from P. Davies) and $\beta$-actin (Sigma).

\section{Amyloid- $\beta$ ELISA measurements}

Soluble and insoluble fractions were extracted from right hippocampus and right cortex as previously described [53]. Briefly, brain samples of each mouse were homogenised in $2 \%$ sodium dodecyl sulphate (SDS) using a Precellys 24Dual (Bertin technologies). Homogenate was centrifuged at $28,300 \mathrm{rpm}$ for $1 \mathrm{~h}$ at $4{ }^{\circ} \mathrm{C}$. The supernatant was carefully removed and stored at $-20{ }^{\circ} \mathrm{C}$ for later analysis as the "soluble" fraction. The insoluble pellet was further dissolved in $70 \%$ formic acid. Samples were centrifuged again at $28,300 \mathrm{rpm}$ for $1 \mathrm{~h}$ at $4{ }^{\circ} \mathrm{C}$. The supernatant was carefully removed and added 1:20 to a neutralising buffer (1 M Tris, $\left.0.5 \mathrm{M} \mathrm{Na}_{2} \mathrm{HPO}_{4}, \mathrm{pH} 11\right)$ and stored at $-20{ }^{\circ} \mathrm{C}$ for subsequent analysis.

Enzyme-linked immunosorbent assay (ELISA) kits specific for human $A \beta 40$ and $A \beta 42$ (Invitrogen:\#KHB3482 and \#KHB3441) and A $\beta 43$ (Tecan: RE59711) were used to quantify soluble and insoluble $A \beta$ species according to the manufacturer's instructions. Results were expressed as picograms (pg) per milligram (mg) of tissue. The mean from duplicate measurements are presented.

\section{ACE1 and ACE2 enzyme activity measurements}

To quantify the enzyme activity of ACE1 and ACE2, we used established fluorogenic assays that have previously been described $[4,5,35,54]$. Brain tissue samples from the left hippocampus and left cortex were dissected and homogenised in 1\% SDS lysis buffer using an automated Precellys tissue homogeniser. ACE1 and ACE2 activities were quantified using an ACE1 fluorogenic peptide Abz-FRK(Dnp)-P (Enzo Life Sciences) in the presence/absence of captopril (Enzo) or an ACE2 substrate peptide Mca-APK(Dnp) in the presence/absence of MLN4760 (Millipore). Specific enzyme activity was calculated by subtracting the fluorescence in the presence of the specific inhibitor from total fluorescence without inhibition.

\section{ACE2 protein level measurement}

Total protein levels of ACE2 were measured in the right hippocampus by ELISA according to the manufacturer's instructions (Abcam: ab213843).

\section{Angiotensin-I, -II and -(1-7) measurement}

Levels of Ang-I, Ang-II, Ang-(1-7) were measured in hippocampal homogenates prepared in 1\% SDS using in-house direct ELISA's, as previously described for the quantification of peptides in human postmortem brain tissue and CSF [4, 5, 35, 36, 54]. In brief, serial dilutions of recombinant Ang-I, Ang-II or Ang-(1-7) (5000-78.125 pg/ml) (Abcam, Cambridge, UK), and mouse brain extracts (diluted 1 in 20 in PBS) were coated on a Nunc Maxisorp 96-well plate (ThermoFisher Scientific, Waltham, MA, USA) for $2 \mathrm{~h}$ at room temperature on a plate shaker (300 rpm), washed, and incubated with biotinylated detection antibodies [biotinylated anti-Ang-I (diluted 1 in 100 in PBS); biotinylated anti-AngII (diluted 1 in 500 in PBS) or biotinylated anti-Ang-(1-7) (diluted 1 in 100 in PBS) (all from Cloud-Clone, Wuhan, China)] for another $2 \mathrm{~h}$ with shaking. After washing and incubation with streptavidin:HRP (diluted 1 in 200 in $0.1 \%$ PBS:Tween-20) (R\&D systems) for $20 \mathrm{~min}$, the plates were washed and incubated with TMB substrate (R\&D systems). The reaction was stopped after $20 \mathrm{~min}$ and absorbance was read at $450 \mathrm{nM}$ using a FLUOstar OPTIMA plate reader (BMG Labtech, Aylesbury, BUCKS, UK). Samples were measured in duplicate and interpolated from the serial dilution of recombinant protein.

\section{Cytokine measurements}

ELISA kits specific for mouse interleukin (IL)- $1 \beta$, IL-6 and IL-10 and TNF- $\alpha$ (R\&D Systems: DY401, DY406, DY417, DY410) were used to quantify cytokine levels in hippocampal soluble sample extracts. Results were expressed as pg/ $\mathrm{mg}$. Means from duplicate readings are presented.

\section{Microglial (CD68 and IBA1) and astrocyte (GFAP) ELISA}

The level of an astrocytic activation marker (GFAP) and two independent microglial markers (IBA1 and CD68) were measured in hippocampal samples homogenised in 1\% SDS buffer using commercial ELISA kits following the manufacturer's protocols: GFAP (samples diluted 1 in 2000) (Cat no: SEA068Mu), IBA1 (samples diluted 1:200 in PBS) (Cat no. SEC288Mu) (Cloud Clone, Wuhan, China) and CD68 (samples diluted 1 in 650 in PBS) (Cat no. OKEH03503, Aviva Systems Biology, San Diego, USA). 


\section{Vascular markers of tissue oxygenation and BBB leakiness}

The level of VEGF was measured in hippocampal lysates diluted 1 in 40 in PBS using a commercially available ELISA kit (Cat no. DY493, R\&D systems) (MA, USA). The ratio of MAG:PLP is a marker of tissue oxygenation previously developed in studies using human postmortem brain tissue $[55,56]$. MAG was measured in hippocampal lysates diluted 1 in 650 in PBS using an in-house direct ELISA that showed species cross-reactivity in mice as previously described [55, 57]. PLP concentration was measured in hippocampal samples diluted 4 in 100 in PBS using a commercially available sandwich ELISA following the manufacturer's instructions (Aviva Biological Systems, San Diego, USA).

\section{Immunofluorescent labelling}

Brains hemispheres were fixed in $4 \%$ paraformaldehyde in $0.1 \mathrm{M}$ PBS/PFA for $12 \mathrm{~h}$ at room temperature. Brains were then transferred to $25 \%$ reagent-grade sucrose in $0.1 \mathrm{M}$ PBS. Each brain remained in sucrose until sinking, indicating it was fully saturated (approximately $48 \mathrm{~h}$ ), and was then sliced using a vibratome. $40-\mu \mathrm{m}$ coronal sections of hippocampus were stored at $-20 \mathrm{C}$ in an ethylene-glycol-based cryoprotectant (Sigma, UK) until they were used for immunohistochemical analysis.

\section{Parenchymal $A \beta$ imaging}

Sections were washed in $3 \times 5$-min changes of PBS and $3 \times 5$-min washes in distilled water before being incubated for $10 \mathrm{~min}$ in formic acid. Sections were then washed $3 \times 5 \mathrm{~min}$ in distilled water and equilibrated in PBS before being blocked for $20 \mathrm{~min}$ in 5\% PBS/donkey serum (SigmaAldrich, Dorset, UK). Sections were incubated at $4^{\circ} \mathrm{C}$ overnight with mouse anti-human A $\beta$ (4G8) at 1 in 250 in PBS (Biolegend, San Diego, CA, USA). Sections were washed $3 \times 5 \mathrm{~min}$ in PBS and incubated at room temperature for $1 \mathrm{~h}$ with Alexa Fluor 488 donkey anti-mouse (ThermoFisher UK) at 1 in 500 in PBS. Sections were washed $3 \times 5 \mathrm{~min}$ in PBS and mounted using Vectashield mounting medium with DAPI (Vector Labs, Peterborough, UK).

\section{MasR immunofluorescent labelling}

Sections were washed in $3 \times 5$-min changes of PBS and blocked for $20 \mathrm{~min}$ in 5\% PBS/donkey or goat serum (SigmaAldrich, Dorset, UK). Sections were incubated at $4 \mathrm{C}$ overnight with rabbit anti-MasR (1:100) (Cat no. AAR-013) (Alomone Labs, Tel Aviv, Israel). Sections were washed $3 \times 5 \mathrm{~min}$ in PBS and incubated at room temperature for $1 \mathrm{~h}$ (1 in 500 in PBS) with Alexa Flour 488 donkey anti-rabbit (1 in 500 in PBS) (ThermoFisher, UK). Sections were washed $3 \times 5$ min and mounted using Vectashield mounting medium with DAPI (Vector Labs, Peterborough, UK).

\section{GFAP immunolabelling of reactive astrocytes}

Sections were washed in $3 \times 5$-min changes of PBS and blocked for $20 \mathrm{~min}$ in 5\% PBS/goat serum (Sigma-Aldrich, Dorset, UK). Sections were incubated at $4^{\circ} \mathrm{C}$ overnight with chicken anti-GFAP (1:100) (Cat no. abs4674) (Abcam, Cambridge, UK). Sections were washed $3 \times 5$ min in PBS and incubated at room temperature for $1 \mathrm{~h}$ with Alexa Fluor 594 goat anti-chicken (1 in 500 in PBS) (ThermoFisher, UK). Sections were washed $3 \times 5$ min and mounted using Vectashield mounting medium with DAPI (Vector Labs, Peterborough, UK).

\section{Statistical analysis}

All statistical analyses were performed using IBM SPSS statistics (version 25). The behavioural data conformed to the assumptions of analysis of variance (ANOVA) and were analysed using a mixed measures design. Significant interactions were assessed using tests for simple main effects with Bonferroni correction. Western blot data were analysed using one-way ANOVA followed by Tukey's post hoc analysis. ELISA data were analysed using either an independent-samples $t$ test or one-way ANOVA with post hoc Tukey comparisons. All data were subject to Levene's and Shapiro-Wilks tests for data normality prior to analysis. Appropriate transformations were carried out when necessary. Data generated from ELISA assays were quantified by comparing data to standard curves from each plate using GraphPad Prism ${ }^{\circledR} 7$ and normalised to total protein concentration.

\section{Results}

\section{DIZE reverses associative recognition memory deficits and reduces $A \beta$ pathology in aged Tg2576 mice}

In Experiment 1, WT and Tg2576 mice underwent OiP testing. Contact time data were converted to discrimination ratio (DR) scores (for a full description of OiP object contact times see Supplementary Table 1, online resource). Tests for simple main effects revealed that prior to DIZE administration, both $\mathrm{Tg} 2576$ vehicle $(\mathrm{Tg}-\mathrm{V})$ and $\mathrm{Tg} 2576$ DIZE (Tg-DIZE) mice did not differ significantly but were both impaired compared to WT vehicle (WT-V) controls ( $p=0.0001$ and 0.001 , respectively) (Fig. 2a). Following the 30-day treatment period, $\mathrm{Tg}-\mathrm{V}$ remained impaired 

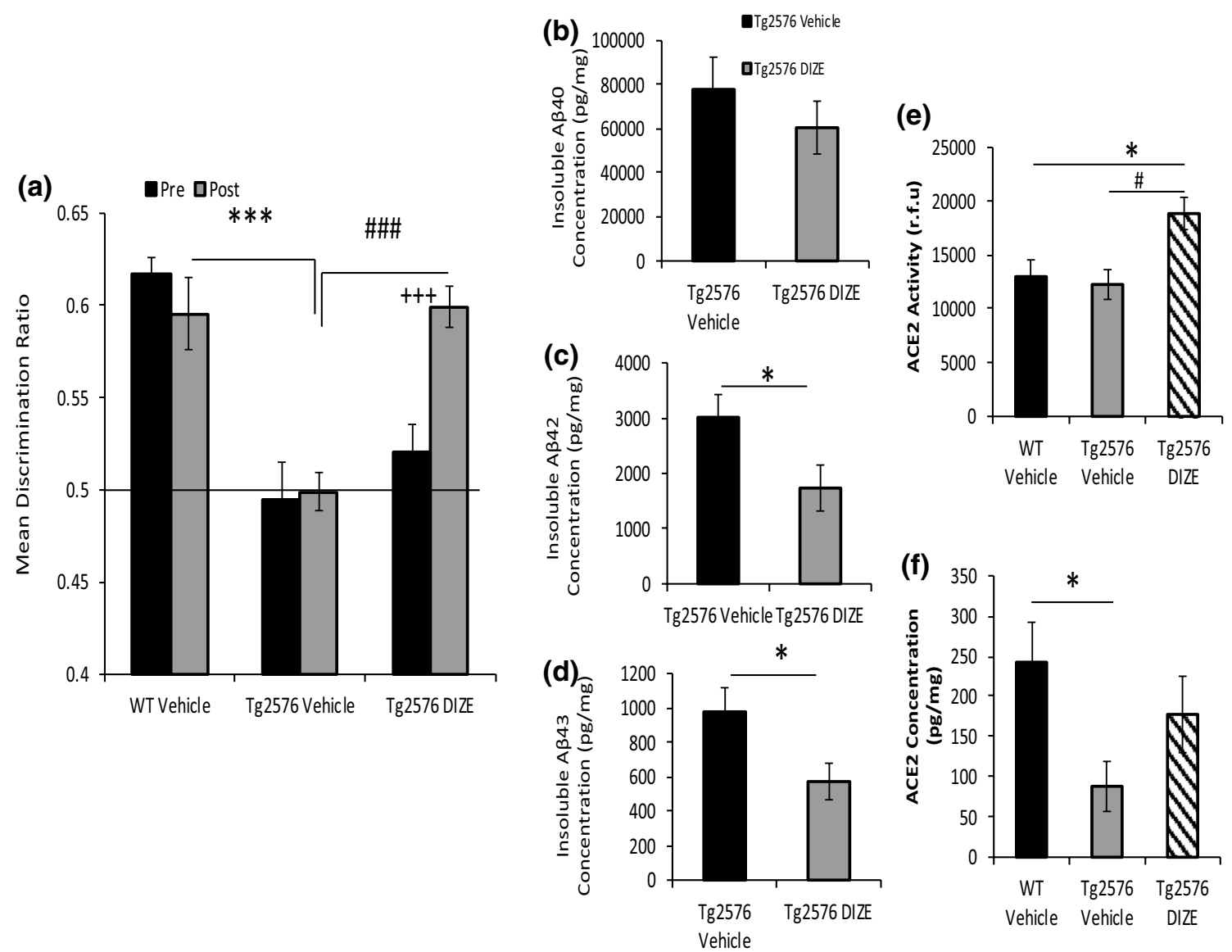

Fig. 2 Improved associative recognition memory and reduced $\mathrm{A} \beta$ pathology in $\operatorname{Tg} 2576$ mice following peripheral administration of DIZE. a Following 30-day IP administration of DIZE $(15 \mathrm{mg} / \mathrm{kg} /$ day), associative recognition memory, tested using the object-inplace (OiP) task, was significantly improved in Tg-DIZE mice $(n=9)$ compared to pre-DIZE scores $\left({ }^{+++} p<0.001\right)$. Tg DIZE mice also performed significantly better than $\mathrm{Tg}$ vehicle mice ${ }^{\# \# \#} p<0.001$; $n=11)$. Tg vehicle mice were impaired compared to WT vehicle mice $(* * * p<0.001 ; n=12)$, whilst Tg-DIZE mice showed a comparable performance level to WT mice, $p>0.1$. b-d Hippocampal insoluble $\mathrm{A} \beta 40, \mathrm{~A} \beta 42$ and $\mathrm{A} \beta 43$ concentration was measured by sandwich ELISA. Insoluble $A \beta 42$ and $A \beta 43$ levels were significantly reduced in the hippocampus in Tg-DIZE compared to $\mathrm{Tg}-\mathrm{V}$ mice $(* p s<0.05)$

compared to WT-V mice $(p=0.0001)$. In contrast, Tg-DIZE mice performed comparably to WT-V mice $(p=1.0)$ and significantly better than $\mathrm{Tg}-\mathrm{V}$ mice $(p=0.0001)$. The Tg-DIZE group showed no overall change in physiological parameters, including body weight, MABP and HR compared to all groups (Supplementary Fig. 2, online resource).

Hippocampal parenchymal A $\beta$ plaque load was visualised using 4G8 immunofluorescent labelling and appeared to be lower in Tg-DIZE mice compared to Tg vehicle (Supplementary Fig. 3, online resource). To confirm our immunohistochemical observations, we measured insoluble $A \beta 40$, $\mathrm{A} \beta 42$, and $\mathrm{A} \beta 43$ (an early-depositing and highly amyloidogenic seed that is cleaved by ACE2), in hippocampal extracts

whereas A 340 was unchanged. e Hippocampal ACE2 activity, quantified using a FRET enzyme activity assay, was significantly elevated in the hippocampus of Tg DIZE compared to WT vehicle $(* p<0.05)$ and $\mathrm{Tg}$ vehicle $\left(\mathrm{p}^{\#}<0.05\right)$ mice. f Hippocampal ACE2 level, measured by ELISA, was lower in Tg vehicle compared to WT vehicle mice $\left(p^{*}<0.05\right)$; no statistically significant difference was observed between WT vehicle and Tg DIZE mice $(p>0.05)$. Behavioural data were analysed using mixed measures ANOVA. Significant interactions were further analysed by tests for simple main effects with Bonferroni corrections for multiple comparisons. Amyloid analysis was performed using independent-samples $t$ test. ACE2 analysis was performed using one-way ANOVA with post hoc Tukey analysis. Error bars represent the standard error of the mean (SEM)
(Fig. 2c, d). Insoluble A $\beta 42(t(18)=2.16, p=0.044)$ and $\mathrm{A} \beta 43(t(18)=2.22, p=0.04)$ were significantly reduced in the hippocampus of Tg-DIZE compared to $\mathrm{Tg}-\mathrm{V}$ mice. Insoluble A $\beta 40$ level was not statistically different between groups although the absolute levels were numerically lower in Tg-DIZE mice $(t(18)=0.89, p=0.39)$.

Hippocampal ACE2 enzyme activity was significantly different between groups $(F(2,30)=5.49, p=0.01)$ and post hoc Tukey analysis revealed significantly elevated ACE2 activity in Tg-DIZE mice compared to WT-V and $\mathrm{Tg}-\mathrm{V}$ mice ( $p=0.028$ and $p=0.013$, respectively) (Fig. 2e). Hippocampal ACE2 protein level was also significantly different between groups $(F(2,30)=3.35, p=0.049)$ and 
post hoc analysis revealed a significant reduction in ACE2 protein level in Tg-V mice compared to WT-V $(p=0.039)$ but no significant difference between WT-V and Tg-DIZE $(p=0.56)$ (Fig. 2f).

\section{DIZE-mediated restoration of associative recognition memory in Tg2576 mice is mediated specifically through ACE2 enhancement and is associated with reduced hippocampal soluble Aß42}

In Experiment 2, we replicated our findings in Experiment 1 in a second cohort (cohort 2) whilst testing the hypothesis that the effects of DIZE on memory were mediated specifically through enhancing ACE2 activity. An additional group of Tg-DIZE mice was co-administered with DIZE +C16 (C16 is an ACE2 antagonist). Contact time data are presented in Supplementary Table 2, online resource. Analysis of OiP discrimination ratios (Fig. 3a) confirmed our findings in Experiment $1 . \mathrm{Tg}-\mathrm{V}(p=0.001)$ and Tg-DIZE $(p=0.001)$ mice were impaired compared to WT-V mice at baseline (pre-treatment). Following 30 days of treatment, $\mathrm{Tg}-\mathrm{V}$ remained cognitively impaired compared to WT mice $(p=0.001)$ but memory performance in Tg-DIZE mice was significantly improved and comparable to WT-V mice. Importantly, the beneficial effect of DIZE was abolished in Tg-DIZE + C16 mice compared to Tg-V mice $(p=0.757)$ (Fig. 3a). Furthermore, Tg-DIZE mice showed better OiP performance compared to $\mathrm{Tg}-\mathrm{V}$ mice $(p=0.001)$ and $\mathrm{Tg}-$ DIZE + C16 mice $(p=0.001)$.

As for Experiment 1, DIZE significantly altered hippocampal ACE2 activity $(F(3,83)=6.42, p=0.0001)$, which was increased in Tg-DIZE mice compared to WT-V $(p=0.003)$ and $\mathrm{Tg}-\mathrm{V}$ mice $(p=0.001)$ (Fig. 3b). No change in ACE2 activity was observed in Tg-DIZE + C16 mice compared to either WT-V or Tg-V group ( $p \mathrm{~s}>0.05)$. Although hippocampal ACE1 activity was numerically reduced in $\mathrm{Tg}$ DIZE mice compared to $\mathrm{Tg}-\mathrm{V}$ mice, it did not reach conventional levels of statistical significance $(p>0.05)$. However, the ratio of ACE2:ACE1 was significantly increased in $\mathrm{Tg}$ DIZE mice compared to $\mathrm{Tg}-\mathrm{V}$ mice $(p<0.01)$.

Hippocampal insoluble $A \beta 42$ and $A \beta 43$ levels were both significantly reduced in Tg-DIZE mice compared to $\mathrm{Tg}-\mathrm{V}$ mice ( $p=0.010$ and $p=0.009$, respectively). Hippocampal insoluble $A \beta 42$ and $A \beta 43$ levels also remained significantly lower in Tg-DIZE $+\mathrm{C} 16$ mice $(p=0.0018$ and $p=0.002$, respectively) compared to $\mathrm{Tg}-\mathrm{V}$ mice (Fig. 3c). The same trend was observed for insoluble $\mathrm{A} \beta 40$ but did not reach statistical significance $F(2,53)=3.026, p=0.057$ (Fig. 3c). All species of soluble $A \beta$ levels were numerically lower but not significantly altered in Tg-DIZE mice compared to $\mathrm{Tg}-\mathrm{V}$ (Fig. 3c) (a detailed breakdown of the percentage change in $\mathrm{A} \beta$ species across experimental groups is shown in Supplementary Table 5, online resource). Soluble A $\beta 42$ was, however, significantly higher in the Tg-DIZE + C16 mice compared to the Tg-DIZE mice $(p=0.0037)$ (Fig. 3c).

\section{DIZE-associated cognitive improvement is associated with restored Mas receptor expression and enhanced glutamate receptor signalling in hippocampal synaptosomes}

In Experiment 3, we again confirmed DIZE-mediated improvement in OiP DR scores in Tg-DIZE mice in a separate cohort of mice (cohort 3) (Fig. 4a) (a detailed assessment of contact time and DR scores is shown in Supplementary Table 3, online resource). MasR was abundantly expressed in the hippocampus, specifically in the dentate gyrus and subiculum (Supplementary Fig. 4a, online resource) and appeared to be reduced in Tg-V mice compared to WT-V mice (Supplementary Fig. 4b, online resource). We were unable to quantify IF-labelling but MasR level measured by ELISA was reduced in Tg-2576 compared to WT mice ( $<<0.05)$ (Supplementary Fig. 4c, online resource). MasR expression appeared to be increased in Tg-DIZE compared to $\mathrm{Tg}-\mathrm{V}$ mice in hippocampal synaptosomes assessed by western blot (Fig. 4b). On analysis, a significant group effect was observed in the level of MasR expression, $(F(3$, $27)=3.55, p=0.029)$. Post hoc Tukey analysis revealed that MasR level was significantly increased in Tg-DIZE mice compared to $\mathrm{Tg}-\mathrm{V}$ mice $(p=0.041)$ (Fig. $4 \mathrm{c})$. In contrast, the level of the insulin-regulated aminopeptidase receptor (IRAP) (also involved in downstream rRAS signalling) was unchanged across groups $(F(3,27)=1.99, p=0.14)$.

In hippocampal synaptosomal extracts, the ratio of phosphorylated NR2B to total NR2B was altered between groups $F(3,27)=5.23, p=0.006$ and post hoc Tukey analysis revealed that in Tg-DIZE, the ratio was increased compared to Tg-V mice $(p=0.012)$ and also in WT-DIZE compared to Tg-V mice ( $p=0.011)$ (Fig. 4e). No significant change was observed in total levels of GluA1 or GluA1 phosphorylated at regulatory Ser845 (maximal effect, $F(3,27)=1.35$, $p=0.28$ (pGluA1), and total levels of PSD95 were unchanged $F(3,27)=0.49, p=0.70$ (Fig. 4f). In addition, the level of phosphorylated ERK was significantly altered, $F(3,27)=8.59, p=0.001$. Post hoc Tukey analysis showed increased phosphorylated ERK in both Tg-DIZE $(p=0.001)$ and WT-DIZE mice $(p=0.032)$ compared to respective vehicle controls; in contrast, total ERK was unchanged across groups, $F(3,27)=0.36, p=0.79$ (Fig. 4d) (full blots of all samples analysed are shown in Supplementary Fig. 5, online resource).

Given that tau has been shown to play a role in learning and is commonly hyperphosphorylated in $\mathrm{AD}[58,59]$, we further measured levels of tau phosphorylation in hippocampal synaptosomes. However, no significant differences were 

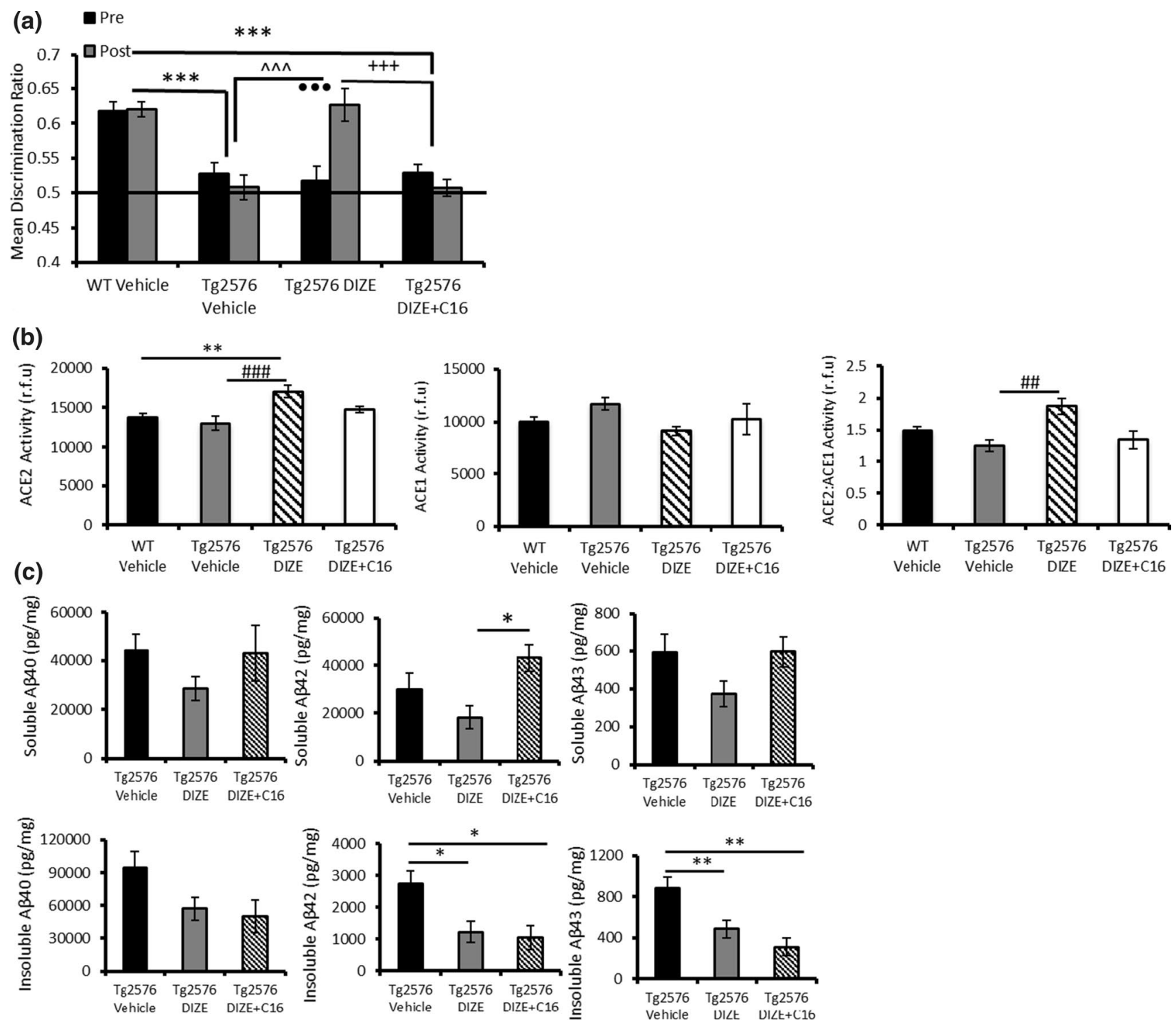

Fig. 3 DIZE-mediated restoration of the recognition associative memory deficit in $\operatorname{Tg} 2576$ mice is mediated by enhanced ACE2 and is associated with reduced soluble $\mathrm{A} \beta 42$. a Associative recognition memory was impaired in $\mathrm{Tg}$ vehicle mice $(n=12)$ compared to WT vehicle mice $(n=21)(* * * p<0.001)$ and Tg2576 DIZE-administered mice $(n=13)\left({ }^{\wedge \wedge} p<0.001\right)$. DIZE improved the cognitive performance of $\operatorname{Tg} 2576$ mice compared to pre-DIZE administration performance $(\cdots p<0.001)$. Co-administration of DIZE + C16 in $\mathrm{Tg} 2576$ mice $(n=11)$ prevented the improvement compared to pre-administration performance $(p>0.05)$. DIZE $+\mathrm{C} 16$ mice were also impaired compared to WT vehicle $(* * * p<0.001)$ and $\operatorname{Tg} 2576$ DIZE mice $\left({ }^{++} p<0.001\right)$. b Hippocampal ACE2 activity was increased in $\mathrm{Tg} 2576$ DIZE-administered mice $(n=22)$ compared to WT vehicle $(n=33)(* * p<0.01)$ and Tg2576 vehicle mice $(n=23)$ $\left({ }^{\# \#} p<0.001 ; n=23\right)$. Although numerically reduced, no difference was reported in ACE2 activity in Tg2576 mice co-administered

observed between WT and $\mathrm{Tg} 2576$ mice, with or without the administration of DIZE, when comparing total levels of tau $F(3,20)=0.70, p=0.56$ or tau phosphorylated at
DIZE $+\mathrm{C} 16(p>0.05 ; n=11)$. There was no significant difference in ACE1 activity across groups but the ratio of ACE2:ACE1 was significantly elevated in $\mathrm{Tg} 2576$ DIZE mice compared to $\mathrm{Tg} 2576$ vehicle mice $(p<0.01)$. These changes were not apparent in $\mathrm{Tg} 2576$ mice co-administered DIZE and C16, $p>0.05$. c Soluble and insoluble levels of $A \beta 40, A \beta 42$ and $A \beta 43$, were measured by ELISA. Soluble A $\beta 42$ was significantly lower in Tg2576 DIZE mice compared to mice co-administered DIZE $+\mathrm{C} 16(* p<0.05)$. Insoluble $\mathrm{A} \beta 42$ and 43 was significantly reduced in both $\mathrm{Tg} 2576$ DIZE mice and $\mathrm{Tg} 2576$ mice co-administered DIZE $+\mathrm{C} 16$. Insoluble $\mathrm{A} \beta 40$ was unchanged between Tg-DIZE and Tg-DIZE + C16 mice. Behavioural data were analysed using mixed measures ANOVA. Significant interactions were further analysed by tests for simple main effects with Bonferroni corrections for multiple comparisons. ACE2 and A $\beta$ analysis was performed using one-way ANOVA with post hoc Tukey analysis. Error bars represent the SEM

Ser396/404, $F(3,20)=1.12, p=0.37$ (Supplementary Fig. 6, online resource). This may be indicative of a lack of reported tau changes in $\operatorname{Tg} 2576$ mice at this age and future studies 
(a)

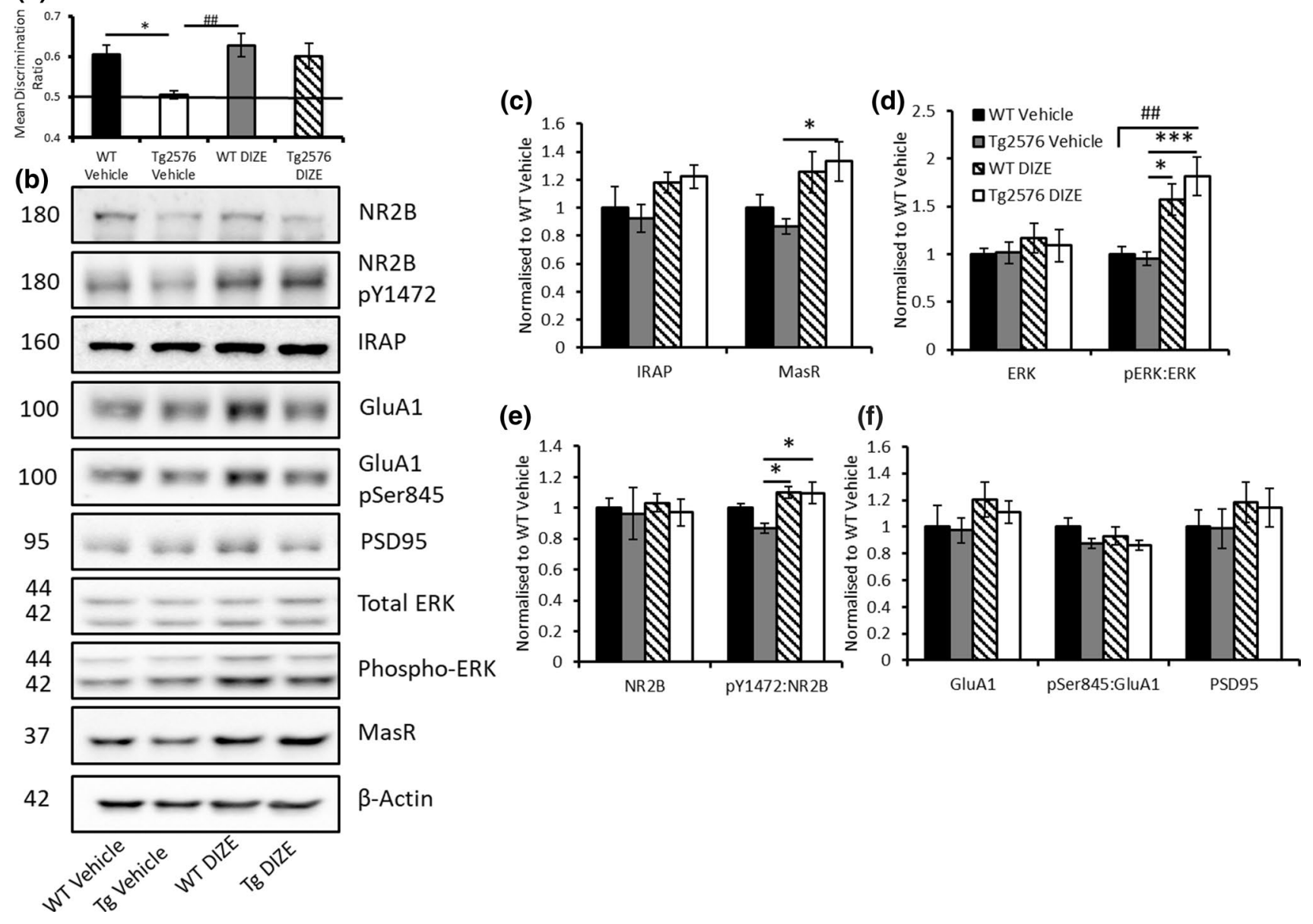

Fig. 4 DIZE-mediated restoration of associative recognition memory in $\mathrm{Tg} 2576$ mice is associated with restored MasR expression and evidence of enhanced NMDA NR2B subunit glutamate signalling. a $\operatorname{Tg} 2576$ vehicle mice $(n=7)$ were impaired compared to both WT vehicle $\left({ }^{*} p<0.05 ; n=7\right)$ and WT DIZE mice $\left({ }^{\# \#} p<0.01 ; n=7\right)$. However, $\operatorname{Tg} 2576$ mice administered DIZE $(n=7)$ showed comparable DR scores to both WT groups, $p s>0.05$. b Representative western blot images showing altered levels of RAS receptor and markers of glutamate-mediated LTP signalling in synaptosome-enriched fractions from the hippocampus. c MasR level was significantly increased in $\operatorname{Tg} 2576$ DIZE mice compared to $\mathrm{Tg} 2576$ vehicle $(* p<0.05)$ whereas IRAP level remained unchanged. d To indicate changes in synaptic signalling, ERK and phospho-ERK were also probed for

should focus on tau changes in older $\operatorname{Tg} 2576$ mice and/or more specifically in rodent transgenic tau models.

\section{ACE2-mediated improvement in associative recognition memory is related to reduced inflammatory (IL-1 $\beta$ ) but not to markers of astrocyte, microglial or vascular function}

Hippocampal IL-1 $\beta$ level was significantly altered between groups $(F(3,87)=5.292, p=0.002)$ and was significantly increased in Tg-V mice compared to WT control $(p=0.018)$ in hippocampal synaptosomes. No changes in total levels of ERK were reported $(p>0.05)$. However, when phosphorylated ERK was normalised to total ERK, there was a significant increase in p-ERK in Tg2576 DIZE mice compared to WT vehicle mice $(\# p<0.01)$. There was also an increase in p-ERK in WT DIZE mice $(* p<0.05)$ and $\mathrm{Tg} 2576$ DIZE mice $(* * * p<0.001)$ compared to WT-V. e Total levels of NR2B were unchanged across groups $(p>0.05)$ but the ratio of phosphorylated Y1472 NR2B:total NR2B was significantly increased in WT DIZE and Tg2576 DIZE compared to Tg2576 vehicle control mice, respectively $(* p s<0.05)$. f No overall change was observed for the post-synaptic marker, PSD95, GluA1 or the ratio of pSer845:GluA1 ( $p s>0.05)$. All data were analysed using one-way ANOVA with post hoc Tukey analysis. Error bars represent the SEM

and significantly reduced in Tg-DIZE mice compared to Tg-V mice $(p=0.015)$ (Fig. 5a) (data was obtained from animals in Experiments 1 and 2). Hippocampal IL-1 $\beta$ level in Tg-DIZE + $\mathrm{C} 16$ mice was comparable to $\mathrm{Tg}-\mathrm{V}$ mice $(p=1.0)$ indicating that the reduction in hippocampal IL-1 $\beta$ in Tg-DIZE mice was specifically related to enhanced ACE2 activity. No significant changes were observed in total levels of hippocampal IL6 $(F(3,87)=2.470, p=0.067)$, IL10 $(F(3,87)=2.053, p=0.113)$, or $\mathrm{TNF} \alpha(F(3,87)=1.555$, $p=0.206)$ in $\mathrm{Tg} 2576$ mice (Fig. 5a). 

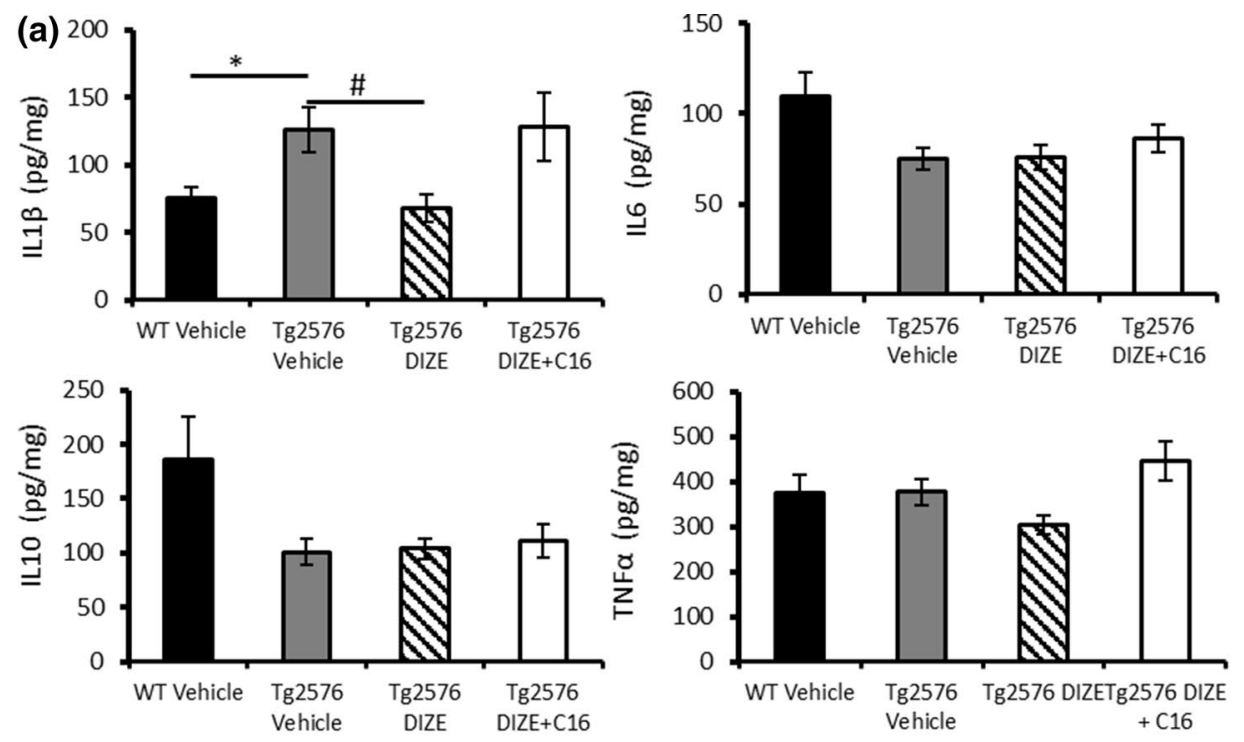

(b)
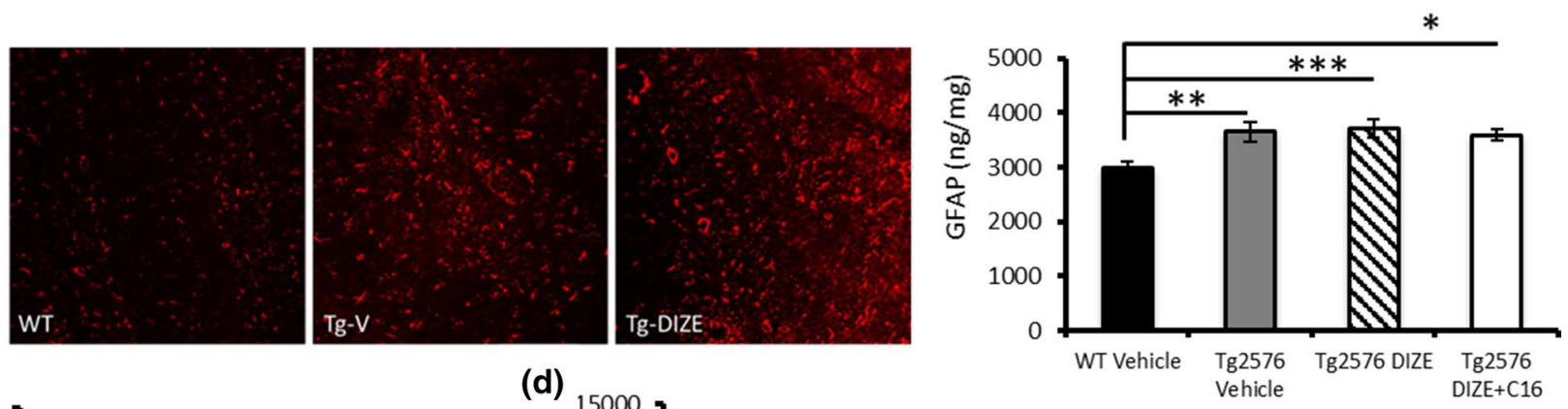

(c)

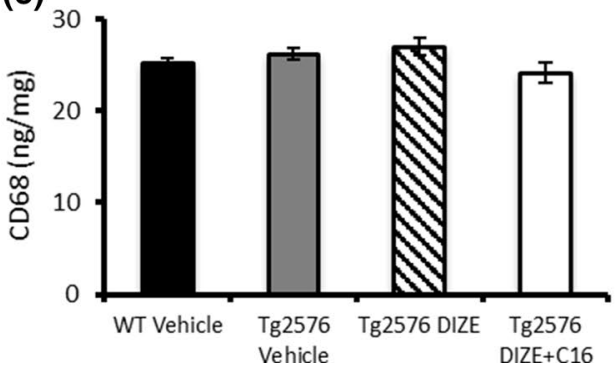

(d)

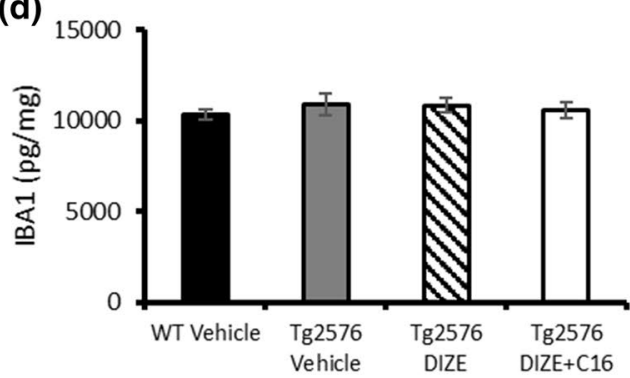

Fig. 5 ACE2-mediated restoration of associative recognition memory is associated with reduced IL- $1 \beta$ but not astrocytic or microglial activation. a Hippocampal IL-1 $\beta$ level, measured by sandwich ELISA, was significantly increased in $\operatorname{Tg} 2576$ vehicle mice $(n=22)$ compared to WT vehicle $(n=34)(* p<0.05)$ and IL-1 $\beta$ was significantly reduced in Tg2576 DIZE mice $(n=21)$ compared to Tg vehicle mice $\left({ }^{\#} p<0.05\right)$. IL1- $\beta$ was not statistically different, however, between $\mathrm{Tg}$ vehicle and $\mathrm{Tg} 2576$ mice co-administered with DIZE +C16 $(n=11)(p s>0.05)$. No overall change was observed in the level of IL6, IL10 or TNF $\alpha$ between groups ( $p s>0.05)$. b Representative

Hippocampal reactive astrocytes were immuno-fluorescently labelled with GFAP in the hippocampus and inspection of the sections suggested that they were more abundantly expressed in $\mathrm{Tg}-\mathrm{V}$ and Tg-DIZE mice compared to WT-V mice (Fig. 5b). Our observations were confirmed by ELISA measurements that showed alterations in GFAP level across groups $(F(3,54)=2.055, p=0.012)$ with post hoc images of GFAP-positive astrocytes within the hippocampus in WT, $\mathrm{Tg}-\mathrm{V}$ and Tg-DIZE mice. GFAP level, measured by ELISA, was significantly increased in Tg2576 vehicle mice $(p<0.01)$, Tg2576 DIZE $(p<0.001)$ and Tg2576 DIZE + C16 mice $(p<0.05)$ compared to WT vehicle. c, $\mathbf{d}$ Two independent microglial markers were measured in hippocampal extracts but no overall changes in concentration were observed $(p>0.05)$. Cytokines and markers of activated microglia and astrocytes were quantified by ELISA. Data were analysed using one-way ANOVA with post hoc Tukey analysis. Error bars represent SEM

analysis revealing that GFAP was significantly increased in all Tg groups compared to WT-V: Tg-V $(p=0.004)$; TgDIZE $(p=0.001)$ and Tg-DIZE +C16 $(p=0.015))($ Fig. 5b). We measured the level of two independent markers of microglia, IBA1 and CD68, in hippocampal homogenates and found no significant difference between $\mathrm{Tg} 2576$ and WT mice, or in the treated Tg mice group (ps $>0.05$; Fig. $5 c$, d). 
(a)

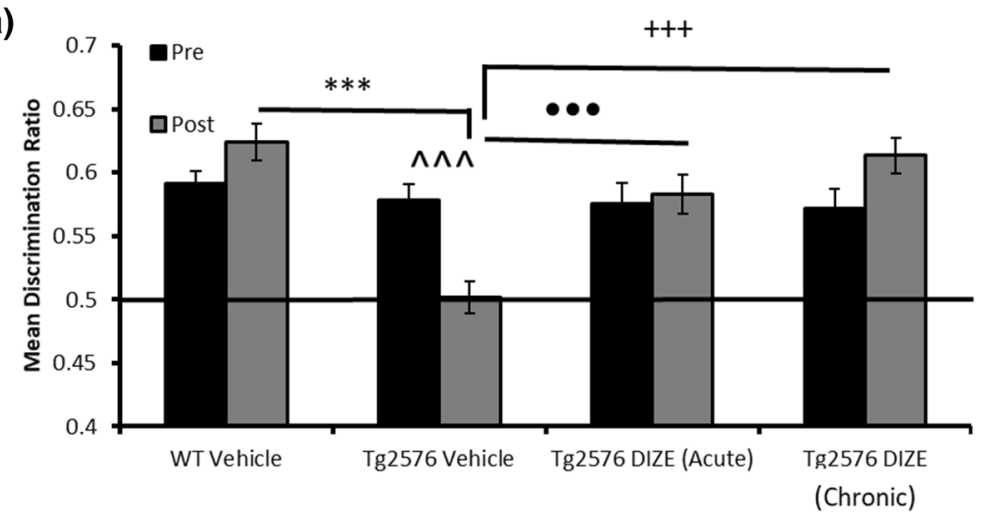

(b)

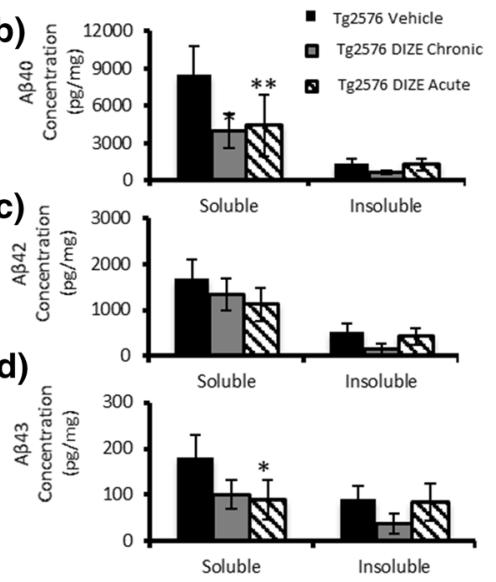

(e)

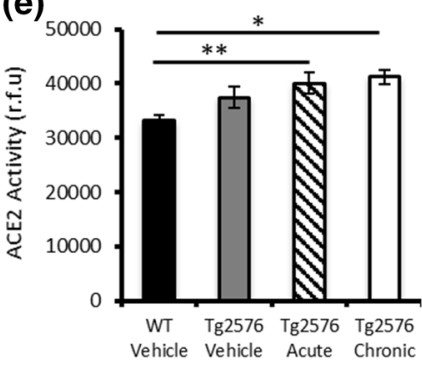

(f)

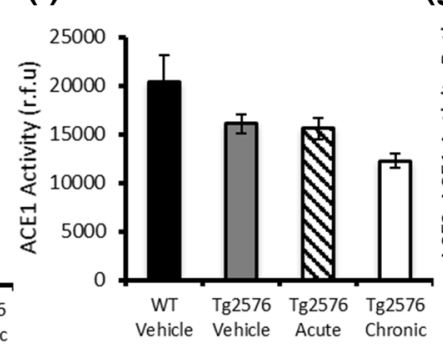

(g)

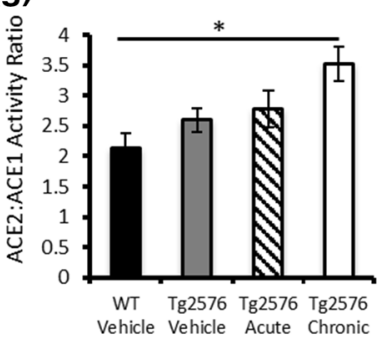

(h)

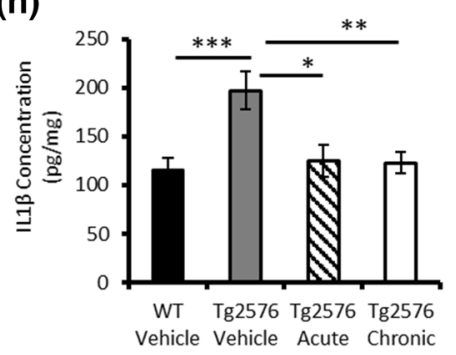

Fig. 6 Acute and chronic administration of DIZE prevents the onset of cognitive impairment in young pre-symptomatic Tg2576 mice. a Associative recognition memory was assessed in younger WT $(n=20)$ and $\operatorname{Tg} 2576$ mice (9-12 months of age) that received either acute (10 days; $n=17$ ) or chronic (10 weeks $n=11)$ DIZE administration. $\mathrm{Tg} 2576$ vehicle mice $(n=16)$ showed an age-dependent impairment in OiP performance $\left({ }^{\wedge \wedge} p<0.001\right)$, which was not observed in either the acute or chronic DIZE-administered Tg2576 mice ( $p s>0.05) . \operatorname{Tg} 2576$ vehicle mice were also impaired compared to WT vehicle $(* * * p<0.001), \operatorname{Tg} 2576$ acute $\left({ }^{* * \bullet} p<0.001\right)$ and $\operatorname{Tg} 2576$ chronic DIZE administered mice $\left({ }^{+++} p<0.001\right)$. b-d A $\beta$ levels were quantified by ELISA. Soluble A $\beta 40$ level was reduced in both chronic $(* p<0.05)$ and acute DIZE-administered Tg2576 mice $(* * p<0.01)$ compared to $\mathrm{Tg} 2576$ vehicle mice. Soluble $\mathrm{A} \beta 43$ was reduced in $\mathrm{Tg} 2576$ mice that received acute DIZE administration $\left({ }^{*} p<0.05\right)$ compared to Tg2576 vehicle mice. e-g ACE2 and ACE1 activities were determined by enzyme activity assays. ACE2 activity was sig-

We also measured two independent markers of tissue oxygenation, VEGF and the ratio of MAG:PLP, based on biochemical assays recently developed in postmortem human brain tissue $[55,56]$. The level of $\operatorname{VEGF}(\mathrm{F}(3,54)=0.24$, $p=0.87)$, a marker of ischaemia, and the ratio of MAG:PLP $(\mathrm{F}(3,54)=2.36, p=0.083)$, a marker of tissue oxygenation that is lowered as a result of reduced perfusion, were both unaltered in the hippocampus across WT and treated $\mathrm{Tg}$ mice (Supplementary Fig. 7, online resource). nificantly increased in the hippocampus of Tg2576 mice administered DIZE either acutely $(* * p<0.01)$ or chronically $(p<0.05)$ compared to WT vehicle mice. Despite a numerical reduction in ACE1 activity in DIZE administered mice, no significant changes were reported, $p>0.05$; however, the ratio of ACE2:ACE1 was significantly increased in Tg-chronic mice compared to WT vehicle $(* p<0.05)$. $\mathbf{h}$ IL-1 $\beta$ level was increased in Tg2576 vehicle mice compared to WT vehicle controls $(* * * p<0.001)$ but was significantly reduced after acute $(* p<0.05)$ and chronic $(* * p<0.01)$ DIZE administration in $\operatorname{Tg} 2576$ mice compared to $\mathrm{Tg}$ vehicle mice. Behavioural data were analysed using mixed measures ANOVA. Significant interactions were further analysed by tests for simple main effects with Bonferroni corrections for multiple comparisons. ACE2 and IL- $1 \beta$ analyses were performed using one-way ANOVA with post hoc Tukey analysis. Amyloid analysis was performed using non-parametric Kruskal-Wallis one-way ANOVA with multiple comparisons. Error bars represent the SEM

\section{DIZE prevented the onset of cognitive impairment and amyloid pathology when delivered to asymptomatic (young) Tg2576 mice}

In Experiment 4, contact times (Supplementary Table 4, online resource) and DR scores (Fig. 6a) revealed that 9-10-month-old Tg-V and Tg-DIZE mice were able to discriminate objects in novel locations (i.e. were unimpaired) prior to treatment (ps>0.9). At 12-13 months of age, when re-tested, $\mathrm{Tg}-\mathrm{V}$ mice were impaired in the OiP task compared to baseline scores $(p=0.001)$ and compared to WT vehicle mice $(p=0.0001)$. In contrast, $\operatorname{Tg} 2576$ mice administered 
DIZE over a 10-week period starting at 9-10 months of age (asymptomatic) (Tg-DIZE chronic) $(p=0.0001)$ and $\mathrm{Tg} 2576$ mice administered DIZE for 10 days at 12-13 months of age (impaired) (Tg-DIZE acute) ( $p=0.001)$ both performed significantly better than $\mathrm{Tg}-\mathrm{V}$ mice and were indistinguishable from WT-V controls mice ( $\mathrm{ps}>0.1)$.

In 12-13-month-old $\mathrm{Tg}-\mathrm{V}$ mice, soluble $\mathrm{A} \beta$ levels were considerably higher than insoluble $A \beta$. Soluble $\mathrm{A} \beta 40(\mathrm{H}(2)=8.07, p=0.018)$ and $\mathrm{A} \beta 43(\mathrm{H}(2)=7.97$, $p=0.019)$ level significantly differed in chronic and acute DIZE-treated mice compared to Tg-V (Fig. 6b-d). Post hoc Dunn's analysis confirmed that soluble hippocampal A $\beta 40$ was significantly reduced in both chronic $(51.81 \%)$ $(p=0.035)$ and acute $(48.93 \%)(p=0.007)$ DIZE-treated mice compared to $\mathrm{Tg}-\mathrm{V}$. Soluble hippocampal A $\beta 43$ was significantly reduced in acutely treated $\mathrm{Tg} 2576$ mice compared to vehicle controls $(52.07 \%)(p=0.014)$ and numerically reduced by $41.88 \%$ in chronic-treated mice $(p=0.44)$. Soluble $\mathrm{A} \beta 42$ was numerically reduced in acute-treated $(43.25 \%)(p=0.41)$ and chronic-treated $(28.25 \%)(p=0.89)$ mice compared to $\mathrm{Tg}-\mathrm{V}$ but due to variability between individual mice, the difference was not statistically significant. All percentage changes in acute and chronic DIZE mice are shown in detail in Supplementary Table 5, online resource.

Hippocampal ACE2 activity was significantly higher in Tg-DIZE mice after acute $(p=0.010)$ and chronic $(p=0.013)$ administration compared to WT-V (Fig. 6e). As previously found in older mice, ACE1 was incrementally reduced in relation to duration of DIZE treatment and the ratio of ACE2:ACE1 was significantly higher in Tg-DIZE mice compared to WT-V (p<0.05) (Fig. 6f-g).

Hippocampal IL-1 $\beta$ level was significantly increased in Tg-V mice compared to WT-V $(p=0.001)$ but was significantly reduced in $\mathrm{Tg} 2567$ mice following both chronic $(p=0.007)$ and acute $(p=0.016)$ exposure to DIZE (Fig. 6h).

\section{Discussion}

In the present study, we have shown for the first time that DIZE-mediated enhancement of brain ACE2 activity prevented cognitive decline when administered chronically to young (9-10 months) asymptomatic Tg25676 mice and restored cognitive performance in aged impaired (13-15 months old) Tg2576 mice. Restoration of cognitive performance in older mice was associated specifically with enhancement of ACE2 activity since DIZE-mediated protection was abolished when co-administered with $\mathrm{C} 16$, an ACE2 inhibitor. DIZE-mediated ACE2 enhancement was specifically associated with changes in soluble $A \beta$, rather than plaque-associated insoluble $A \beta$, within the hippocampus. DIZE, via ACE2, also reduced hippocampal levels of the pro-inflammatory mediator IL-1 $\beta$. We found that DIZE restored hippocampal MAS receptor expression in $\operatorname{Tg} 2576$ mice associated with the evidence of 'activated' glutamatergic signalling processes. DIZE also reinstated the balance of hippocampal RAS activity, i.e. elevated ACE2 and reduced ACE1 activity. Together, these novel data identify a modifiable pathway that has not been previously investigated in a transgenic mouse model of $\mathrm{A} \beta$ pathology and provide mechanistic insights into a potential novel target for therapeutic application in AD.

We have recently shown that the RAS is imbalanced in early-stage AD; overactivity of classical RAS and reduced activity within regulatory RAS are associated with disease pathology in human AD brains [4, 5, 35]. Regulatory RAS (rRAS) pathways are responsible for Ang-II metabolism and counter-balance the detrimental effects of cRAS [60-62]. The Ang-II metabolite, Ang-(1-7), which is the central signalling peptide in $\mathrm{rRAS}$, is the major angiotensin species in the CNS [22, 23] indicating that rRAS pathways likely dominate in the CNS under normal circumstances. Our recent findings in postmortem AD brain tissue $[35,36]$ indicate that ACE2 activity was reduced by almost $50 \%$ in the mid-frontal cortex in AD [35]. The reduction in ACE2 was strongly related to the levels of parenchymal $A \beta$ and tau in contrast to a weaker relationship between ACE1 and $A \beta$, where no association with tau was observed [4]. Moreover, in plasma samples from AD patients, Ang-(1-7) level was similarly found to be reduced and related to cognitive performance [63]. Lower levels of Ang-(1-7) were inversely correlated with accumulation of hyperphosphorylated tau in a naturally occurring accelerated ageing mouse line (SAMP8) and in P301S transgenic overexpressing tau mice [64].

The present study importantly demonstrated that ACE2 enhancement, as a result of peripheral DIZE administration, was specifically responsible for improved cognitive performance and reduced A $\beta$ pathology in transgenic Tg2576 mice. DIZE has centrally acting effects indicating that it either crosses the blood-brain barrier (BBB) or at least influences CNS levels of ACE2. DIZE restored cognitive performance in older symptomatic $\mathrm{Tg} 2576$ mice and protected against cognitive decline in younger pre-symptomatic mice if administered for 10 weeks in 9-10-month-old asymptomatic mice $\mathrm{Tg} 2576$ mice or acutely for 10 days in cognitively impaired 12-13-month-old mice. Our findings are consistent with extensive studies showing cognitive and pathological benefits from enhancing either ACE2 activity or boosting the levels of Ang-(1-7) in mouse models of stroke (reviewed in [65]), chronic cerebral hypoperfusion [66], diabetes [67] and in recent mouse models of $\mathrm{AD}$ where compounds were infused intracerebroventricularly [68, 69]. Interestingly, a direct comparison in an experimental rat model of ischemia/ reperfusion injury recently indicated that rRAS activation, 
by XNT-mediated ACE2 enhancement, was more effective at reducing resultant pathology compared to the cRAS blocker telmisartan, a prototypical ARB [30]. DIZE has previously been shown to protect, following intraperitoneal injection for 8 weeks, against cognitive decline and disease-related pathology in a non-transgenic D-galactose-ovariectomized rat model of $\mathrm{AD}$ [39]. This is the first report of similar protection in an established transgenic model of AD.

Co-administration of DIZE with C16 (an ACE2 inhibitor) $[46,70]$ not only allowed us to confirm the cerebroprotective effects of DIZE were mediated by ACE2 but allowed us to identify ACE2-mediated changes that underpinned cognitive protection. For instance, cognitive protection in Tg2576 mice was associated with changes in soluble $A \beta$ species rather than insoluble $A \beta$ load that presumably reflect parenchymal plaque load. It will be important to identify age-related changes in the soluble and insoluble pools and identify the specific $\mathrm{A} \beta$ species and assemblies that are associated with ACE2 enhancement and cognitive improvement in future studies. Disease pathology and cognitive function is impaired in ACE2 knockout mice providing further support for a role of ACE2 in AD [71]. DIZE reduced hippocampal ACE1 (cRAS) activity in Tg2576 mice, consistent with our previous findings of an inverse relationship between ACE1 and ACE2 in AD human brain tissue [35] and highlights that rRAS and cRAS are inter-dependent and co-regulated.

The downstream activation of MasR is the likely mechanism preserving cognitive function and reducing amyloid pathology in relation to DIZE administration. Ang-(1-7) has been shown to mediate LTP and synaptic plasticity and improve cognition in rodents following activation of MasR, whereas the protective effects were abolished in MasR KO mice $[32,33]$. A meta-analysis recently confirmed the protective role of Ang-(1-7) in cognition [13]. Consistent with this, we observed robust MasR expression within the hippocampus and subiculum in WT mice, as previously shown [31], but found that the expression of MasR was reduced in Tg2576 mice (revealed by IHC and ELISA measurement). Importantly, DIZE restored the expression of MasR in $\mathrm{Tg} 2576$ mice within hippocampal synaptosomal extracts. In contrast, the expression of a related alternative rRAS receptor, IRAP, which is downstream of Ang-II metabolism and also enhances cognitive function and LTP [34, 72] remained unchanged. We also found evidence of increased hippocampal expression of a subset of glutamate receptors and signalling pathways, specifically NR2B receptor and ERK, which influence performance on the OiP task performance in normal mice $[51,73]$. Activation of ERK, which is downstream of NMDA receptor activity, plays a role in regulating memory processes [74]. Deficiencies in synaptic NMDA NR2B subunit phosphorylation and downstream ERK signalling have previously been associated with behavioural deficits in Tg2576, APP23 and 3xTg mice, due in part to the effects of excessive $A \beta$ [75-77]. We have previously shown that changes in the ratio of total:phosphorylated ERK, specifically within synaptosomes, is associated with OiP performance in PDAPP mice [51]. These data indicate that localised changes in synaptosome ERK signalling observed in the DIZE-administered mice are likely to be indicative of increased signalling through the NR2B receptor. Interestingly, we observed similar changes in ERK phosphorylation in WT mice suggesting that DIZE activates hippocampal glutamate signalling in non-diseased mice, i.e. during normal ageing. Future studies should address whether DIZE promotes synaptic and cognitive processes in aged WT mice.

We explored the possible mechanisms that might be associated with DIZE-mediated reduction in diseaserelated pathology and improved cognition in $\mathrm{Tg} 2576$ mice. Overactivation of cRAS is associated with oxidative stress, inflammation, and vascular dysfunction that are likely to contribute to disease pathology and cognitive impairment in $\mathrm{AD}$ (reviewed in [2]). Of the four cytokines studied (IL$1 \beta$, IL-6, IL-10 and TNF- $\alpha$ ), we found that hippocampal IL-1 $\beta$, elevated in Tg2576 mice, was lower and comparable to WT levels following DIZE treatment. As for soluble A $\beta$, reduced IL-1 $\beta$ was specific to ACE2 enhancement (i.e. the effect was not observed in DIZE + C-16 mice) and was specifically associated with restoration and protection against cognitive decline. IL- $1 \beta$ is a pro-inflammatory cytokine that is elevated in $\mathrm{AD}$ (reviewed in [78]) and has previously been shown to impair LTP and learning and memory performance in rodents $[79,80]$. Signalling through the MasR (by Ang(1-7)) exerts anti-inflammatory effects, including reducing IL-1 $\beta$ mRNA levels in cultured microglia [81], which could provide an explanation for the observed protective effects of DIZE. RAS activity, particularly cRAS activation, has also been proposed as an important 'switch' in promoting a pro-inflammatory M1 state, whilst rRAS activity favours an immune-suppressive 'phagocytic' M2 phenotype [82], which could provide a mechanistic explanation for the removal of $\mathrm{A} \beta[83,84]$.

Whilst an attractive hypothesis, our analysis has failed to detect any significant changes in two independent markers of microglial activation (CD68 and IBA1) — a major source of IL-1 $\beta$. However, a more comprehensive analysis of different sub-types of microglial activation markers (particularly markers of M1/M2 phenotype) is required. Comprehensive analysis of these inflammatory markers in WT mice would also provide additional insight into the role of DIZE in mediating cerebroprotection in healthy aged mice and should be a focus of future studies. Astrocytes were constitutively activated in Tg-2576 mice and remained activated in the presence of both DIZE and DIZE $+\mathrm{C} 16$ indicating that astrocyte activation is unlikely to contribute to the observed cognitive protection in $\operatorname{Tg} 2576$ mice at least at this age. The protective effect of DIZE was also not associated, again somewhat surprisingly, given 
the role of RAS in vaso-modulation and blood pressure, with changes in the expression of markers of brain tissue perfusion, VEGF and MAG:PLP (as reviewed in [85]) but this is consistent with our findings of unchanged MABP throughout the study. Given the recent evidence that RAS-targeting ARBs and ACE-Is, associated with reduced incidence and delayed onset of cognitive decline in $\mathrm{AD}$ patients, are associated with reduced tau pathology and lower CSF tau level [14, 86, 87], as well as the ability of the ARB losartan to reverse AngII-mediated tau phosphorylation in aged rodents [8], further studies should address whether DIZE also modifies diseaserelated tau modifications in relation to cognitive decline.

Despite the highly probable involvement of the rRAS pathway in mediating the protective effects of DIZE, we should acknowledge that we did not find an increase in Ang-(1-7) levels in DIZE-treated mice. This may be due to inherent technical difficulties in measuring the level of Ang-(1-7) within brain tissue due to low expression and the short half-life of the peptide; however, it could also indicate the involvement of other rRAS peptides, such as angiotensin-(1-9), that could also potentially activate MasR but which were not measured in this study. Additionally, DIZE-mediated ACE2 activity could act independently of or in combination with rRAS. For instance, ACE2 converts A $\beta 43$, an early-depositing species of $\mathrm{A} \beta$ that has been postulated to be an important seed for parenchymal plaque growth and is elevated in $\mathrm{AD}$ [88], to a less toxic $A \beta$ species via sequential cleavage of $A \beta 43$ to $A \beta 42$ followed by ACE1-mediated cleavage to the less toxic $A \beta 40$ [89]. Thus, DIZE-mediated protection might help promote clearance of this highly amyloidogenic early-depositing form of $\mathrm{A} \beta$. Further studies are, therefore, required to determine the precise pathway/s that underly the protective effects of DIZE before we can begin to translate these promising preclinical findings into the clinic. Given the established influence of gender on RAS activation [90-92], particularly in post-menopausal females, it will also be important to determine if the effects of DIZE are replicated in female mice to inform which patient groups are likely to benefit from rRAS intervention.

Collectively these data indicate the potent cognitive and pathological benefits following DIZE-mediated ACE2 enhancement in a Tg2576 mouse model of AD. Our findings, together with recent data from postmortem brain tissue, reaffirm the importance of the angiotensin hypothesis in $\mathrm{AD}$ and indicate that activation of the regulatory ACE2/Ang-(1-7)/ MasR rRAS pathway, which works to downregulate the cRAS pathway whilst directly boosting memory and learning, provides an exciting, alternative and novel therapeutic target for potential treatment in AD.

Open Access This article is licensed under a Creative Commons Attribution 4.0 International License, which permits use, sharing, adaptation, distribution and reproduction in any medium or format, as long as you give appropriate credit to the original author(s) and the source, provide a link to the Creative Commons licence, and indicate if changes were made. The images or other third party material in this article are included in the article's Creative Commons licence, unless indicated otherwise in a credit line to the material. If material is not included in the article's Creative Commons licence and your intended use is not permitted by statutory regulation or exceeds the permitted use, you will need to obtain permission directly from the copyright holder. To view a copy of this licence, visit http://creativecommons.org/licenses/by/4.0/.

\section{References}

1. Kehoe PG (2018) The coming of age of the angiotensin hypothesis in Alzheimer's disease: progress toward disease prevention and treatment? J. Alzheimer's Dis. 62(3):1443-1466

2. Kehoe PG, Miners S, Love S (2009) Angiotensins in Alzheimer's disease-friend or foe? Trends Neurosci 32(12):619-628

3. Barnes NM, Cheng CHK, Costall B, Naylor RJ, Williams TJ, Wischik CM (1991) Angiofensin converting enzyme density is increased in temporal cortex from patients with Alzheimer's disease. Eur J Pharmacol 200(2-3):289-292

4. Miners JS et al (2008) Angiotensin-converting enzyme (ACE) levels and activity in Alzheimer's disease, and relationship of perivascular ACE-1 to cerebral amyloid angiopathy. Neuropathol Appl Neurobiol 34(2):181-193

5. Miners JS, van Helmond Z, Raiker M, Love S, Kehoe PG (2011) ACE variants and association with brain $A \beta$ levels in Alzheimer's disease. Am J Transl Res 3(1):73

6. Ashby EL, Kehoe PG (2013) Current status of renin-aldosterone angiotensin system-targeting anti-hypertensive drugs as therapeutic options for Alzheimer's disease. Expert Opin Investig Drugs 22(10):1229-1242

7. Li N-C et al (2010) Use of angiotensin receptor blockers and risk of dementia in a predominantly male population: prospective cohort analysis. BMJ 340:b5465

8. Tian M, Zhu D, Xie W, Shi J (2012) Central angiotensin IIinduced Alzheimer-like tau phosphorylation in normal rat brains. FEBS Lett 586(20):3737-3745

9. Yasar S et al (2013) Antihypertensive drugs decrease risk of Alzheimer disease Ginkgo Evaluation of Memory Study. Neurology 81(10):896-903

10. Rozzini L et al (2006) Angiotensin converting enzyme (ACE) inhibitors modulate the rate of progression of amnestic mild cognitive impairment. Int J Geriatr Psychiatry A J Psychiatry Late Life Allied Sci 21(6):550-555

11. Hajjar I et al (2012) Effect of antihypertensive therapy on cognitive function in early executive cognitive impairment: a double-blind randomized clinical trial. Arch Intern Med 172(5):442-444

12. Wharton W, Goldstein FC, Zhao L, Steenland K, Levey AI, Hajjar I (2015) Modulation of renin-angiotensin system may slow conversion from mild cognitive impairment to Alzheimer's disease. J Am Geriatr Soc 63(9):1749-1756

13. Ho JK, Nation DA (2018) Cognitive benefits of angiotensin IV and angiotensin-(1-7): a systematic review of experimental studies. Neurosci Biobehav Rev 92:209-225

14. Wharton W et al (2019) Neurofibrillary tangles and conversion to mild cognitive impairment with certain antihypertensives. $\mathrm{J}$ Alzheimer's Dis 70:1-9

15. Dong Y-F et al (2011) Perindopril, a centrally active angiotensin-converting enzyme inhibitor, prevents cognitive impairment in mouse models of Alzheimer's disease. FASEB J 25(9):2911-2920

16. Danielyan L et al (2010) Protective effects of intranasal losartan in the APP/PS1 transgenic mouse model of Alzheimer disease. Rejuvenation Res 13(2-3):195-201 
17. Ongali B et al (2014) Angiotensin II type 1 receptor blocker losartan prevents and rescues cerebrovascular, neuropathological and cognitive deficits in an Alzheimer's disease model. Neurobiol Dis 68:126-136

18. Kehoe PG et al (2018) The rationale and design of the reducing pathology in Alzheimer's disease through Angiotensin TaRgeting (RADAR) Trial. J. Alzheimer's Dis. 61(2):803-814

19. Hackney ME et al. (2019) Rationale and design of a clinical trial of adapted tango to improve negative health impacts in middle aged African-American female caregivers of persons with alzheimer's disease (ACT Trial). J Alzheimer's Dis, no. Preprint, pp 1-9

20. Ferrario CM, Trask AJ, Jessup JA (2005) Advances in biochemical and functional roles of angiotensin-converting enzyme 2 and angiotensin-(1-7) in regulation of cardiovascular function. Am J Physiol Circ Physiol 289(6):H2281-H2290

21. Ferreira AJ et al (2007) The nonpeptide angiotensin-(1-7) receptor Mas agonist AVE-0991 attenuates heart failure induced by myocardial infarction. Am J Physiol Circ Physiol 292(2):H1113-H1119

22. Chappell MC, Brosnihan KB, Diz DI, Ferrario CM (1989) Identification of angiotensin-(1-7) in rat brain. Evidence for differential processing of angiotensin peptides. J Biol Chem 264(28):16518-16523

23. Pereira MGAG et al (2013) Angiotensin II-Independent Angiotensin-(1-7) Formation in Rat Hippocampus: involvement of Thimet Oligopeptidase. Hypertension 62(5):879-885

24. Feng Y, Xia H, Santos RA, Speth R, Lazartigues E (2010) Angiotensin-converting enzyme 2: a new target for neurogenic hypertension. Exp Physiol 95(5):601-606

25. Jiang T, Gao L, Lu J, Zhang Y-D (2013) ACE2-Ang-(1-7)-Mas axis in brain: a potential target for prevention and treatment of ischemic stroke. Curr Neuropharmacol 11(2):209-217

26. Feng $Y$ et al (2008) Angiotensin-converting enzyme 2 overexpression in the subfornical organ prevents the angiotensin II-mediated pressor and drinking responses and is associated with angiotensin II type 1 receptor downregulation. Circ Res 102(6):729-736

27. Xia H, Feng Y, Obr TD, Hickman PJ, Lazartigues E (2009) Angiotensin II Type 1 receptor-mediated reduction of angiotensin-converting enzyme 2 activity in the brain impairs baroreflex function in hypertensive mice. Hypertension 53(2):210-216

28. L. Xiao, L. Gao, E. Lazartigues, and I. H. Zucker, "Brain-selective overexpression of angiotensin-converting enzyme 2 attenuates sympathetic nerve activity and enhances baroreflex function in chronic heart failure," Hypertension, p. HYPERTENSIONAHA-111, 2011

29. Sriramula S, Cardinale JP, Lazartigues E, Francis J (2011) ACE2 overexpression in the paraventricular nucleus attenuates angiotensin II-induced hypertension. Cardiovasc Res 92(3):401-408

30. Abdel-Fattah MM, Messiha BAS, Mansour AM (2018) Modulation of brain ACE and ACE2 may be a promising protective strategy against cerebral ischemia/reperfusion injury: an experimental trial in rats. Naunyn. Schmiedebergs. Arch. Pharmacol. 391(9):1003-1020

31. M. Freund, T. Walther, and O. von B. und Halbach, "Immunohistochemical localization of the angiotensin-(1-7) receptor Mas in the murine forebrain," Cell Tissue Res., vol. 348, no. 1, pp. 29-35, 2012

32. Hellner K, Walther T, Schubert M, Albrecht D (2005) Angiotensin-(1-7) enhances LTP in the hippocampus through the G-protein-coupled receptor Mas. Mol Cell Neurosci 29(3):427-435

33. Lazaroni TLN et al (2012) Angiotensin-(1-7)/Mas axis integrity is required for the expression of object recognition memory. Neurobiol Learn Mem 97(1):113-123
34. Wright JW, Harding JW (2019) Contributions by the Brain ReninAngiotensin System to Memory, Cognition, and Alzheimer's Disease. J Alzheimer's Dis, no. Preprint, pp 1-12

35. Kehoe PG, Wong S, Mulhim NAL, Palmer LE, Miners JS (2016) Angiotensin-converting enzyme 2 is reduced in Alzheimer's disease in association with increasing amyloid- $\beta$ and tau pathology. Alzheimers Res Ther 8(1):50

36. Kehoe PG, Hibbs E, Palmer LE, Miners JS (2017) Angiotensin-III is increased in Alzheimer's disease in association with amyloid- $\beta$ and tau pathology. J Alzheimer's Dis 58(1):203-214

37. Vickers $C$ et al (2002) Hydrolysis of biological peptides by human angiotensin-converting enzyme-related carboxypeptidase. J Biol Chem 277(17):14838-14843

38. Elased KM, Cunha TS, Marcondes FK, Morris M (2008) Brain angiotensin-converting enzymes: role of angiotensin-converting enzyme 2 in processing angiotensin II in mice. Exp Physiol 93(5):665-675

39. Kamel AS, Abdelkader NF, El-Rahman SSA, Emara M, Zaki HF, Khattab MM (2018) Stimulation of ACE2/ANG (1-7)/Mas axis by diminazene ameliorates Alzheimer's disease in the D-galactose-ovariectomized rat model: role of PI3K/Akt pathway. Mol Neurobiol 55(10):8188-8202

40. Lanz TA, Hosley JD, Adams WJ, Merchant KM (2004) Studies of A $\beta$ pharmacodynamics in the brain, cerebrospinal fluid, and plasma in young (plaque-free) $\operatorname{Tg} 2576$ mice using dibenzo [b, d] azepin-7-yl]-L-alaninamide (LY-411575). J Pharmacol Exp Ther 309(1):49-55

41. Alexander G, Hanna A, Serna V, Younkin L, Younkin S, Janus C (2011) Increased aggression in males in transgenic Tg2576 mouse model of Alzheimer' s disease. Behav Brain Res 216(1):77-83

42. Hsiao $\mathrm{K}$ et al (1996) Correlative memory deficits, A $\beta$ elevation, and amyloid plaques in transgenic Mice. Science 274(5284):99-103

43. Bruce EB et al (2018) ACE2 activator diminazene aceturate reduces adiposity but preserves lean mass in young and old rats. Exp Gerontol 111:133-140

44. Goru SK, Kadakol A, Malek V, Pandey A, Sharma N, Gaikwad AB (2017) Diminazene aceturate prevents nephropathy by increasing glomerular ACE2 and AT2 receptor expression in a rat model of type1 diabetes. Br J Pharmacol 174(18):3118-3130

45. Dales NA et al (2002) Substrate-based design of the first class of angiotensin-converting enzyme-related carboxypeptidase (ACE2) inhibitors. J Am Chem Soc 124(40):11852-11853

46. Kim M-A et al (2010) Effects of ACE2 inhibition in the postmyocardial infarction heart. J Card Fail 16(9):777-785

47. Yan Fei Q et al (2013) Diminazene aceturate enhances angiotensin-converting enzyme 2 activity and attenuates ischemia-induced cardiac pathophysiology. Hypertension 62(4):746-752

48. Hale G, Good M (2005) Impaired visuospatial recognition memory but normal object novelty detection and relative familiarity judgments in adult mice expressing the APPswe Alzheimer's disease mutation. Behav Neurosci 119(4):884-891

49. Good MA, Hale G (2007) The 'Swedish' mutation of the amyloid precursor protein (APPswe) dissociates components of object-location memory in aged $\operatorname{Tg} 2576$ mice. Behav Neurosci 121(6):1180-1191

50. Ennaceur A, Delacour J (1988) A new one-trial test for neurobiological studies of memory in rats. 1: behavioral data. Behav Brain Res 31(1):47-59

51. Evans CE, Thomas RS, Freeman TJ, Hvoslef-Eide M, Good MA, Kidd EJ (2019) Selective reduction of APP-BACE1 activity improves memory via NMDA-NR2B receptor-mediated mechanisms in aged PDAPP mice. Neurobiol Aging 75:136-149

52. Evans C, Hvoslef-Eide M, Thomas R, Kidd E, Good MA (2018) A rapidly acquired foraging-based working memory task, sensitive to hippocampal lesions, reveals age-dependent and 
age-independent behavioural changes in a mouse model of amyloid pathology. Neurobiol Learn Mem 149:46-57

53. Lelos MJ, Thomas RS, Kidd EJ, Good MA (2011) Outcome-specific satiety reveals a deficit in context-outcome, but not stimulus- or action-outcome, associations in aged Tg2576 mice. Behav Neurosci 125(3):412-425

54. Miners S et al (2009) Angiotensin-converting enzyme levels and activity in Alzheimer's disease: differences in brain and CSF ACE and association with ACE1 genotypes. Am J Transl Res 1(2):163

55. Barker R, Wellington D, Esiri MM, Love S (2013) Assessing white matter ischemic damage in dementia patients by measurement of myelin proteins. J Cereb Blood Flow Metab 33(7):1050-1057

56. Thomas T, Miners S, Love S (2015) Post-mortem assessment of hypoperfusion of cerebral cortex in Alzheimer's disease and vascular dementia. Brain 138(4):1059-1069

57. Miners JS, Palmer JC, Love S (2016) Pathophysiology of hypoperfusion of the precuneus in early A lzheimer's disease. Brain Pathol 26(4):533-541

58. Regan $\mathrm{P}$ et al (2015) Tau phosphorylation at serine 396 residue is required for hippocampal LTD. J Neurosci 35(12):4804-4812

59. Morris M, Maeda S, Vossel K, Mucke L (2011) The many faces of tau. Neuron 70(3):410-426

60. Santos RAS, Campagnole-Santos MJ, Andrade SP (2000) Angiotensin-(1-7): an update. Regul Pept 91(1-3):45-62

61. Santos FN et al (2003) Angiotensin-(1-7) is an endogenous ligand for the $G$ protein-coupled receptor Mas. Proc Natl Acad Sci 100(14):8258-8263

62. Ferreira AJ, Santos RAS (2005) Cardiovascular actions of angiotensin-(1-7). Braz J Med Biol Res 38(4):499-507

63. Jiang $\mathrm{T}$ et al (2016) Plasma angiotensin-(1-7) is a potential biomarker for Alzheimer's disease. Curr Neurovasc Res 13(2):96-99

64. Jiang T et al (2016) Angiotensin-(1-7) is reduced and inversely correlates with tau hyperphosphorylation in animal models of Alzheimer's disease. Mol Neurobiol 53(4):2489-2497

65. Regenhardt RW, Bennion DM, Sumners C (2014) Cerebroprotective action of angiotensin peptides in stroke. Clin Sci 126(3):195-205

66. Xie W, Zhu D, Ji L, Tian M, Xu C, Shi J (2014) Angiotensin-(1-7) improves cognitive function in rats with chronic cerebral hypoperfusion. Brain Res 1573:44-53

67. Zhang D, Xiao Q, Luo H, Zhao K (2015) Effects of angiotensin-(1-7) on hippocampal expressions of GFAP and GDNF and cognitive function in rats with diabetes mellitus. Nan Fang Yi Ke Da Xue Xue Bao 35(5):646-651

68. Uekawa $\mathrm{K}$ et al (2016) Intracerebroventricular infusion of angiotensin-(1-7) ameliorates cognitive impairment and memory dysfunction in a mouse model of Alzheimer's disease. J Alzheimer's Dis 53(1):127-133

69. Cao C, Hasegawa Y, Hayashi K, Takemoto Y, Kim-Mitsuyama S (2019) Chronic angiotensin 1-7 infusion prevents angiotensinII-induced cognitive dysfunction and skeletal muscle injury in a mouse model of Alzheimer's disease. J Alzheimer's Dis, pp 1-13

70. Tikellis C, Brown R, Head GA, Cooper ME, Thomas MC (2014) Angiotensin-converting enzyme 2 mediates hyperfiltration associated with diabetes. Am J Physiol Physiol 306(7):F773-F780

71. Wang X-L et al (2016) Deficiency of angiotensin-converting enzyme 2 causes deterioration of cognitive function. Npj Aging Mech Dis 2:16024

72. Benoist CC, Wright JW, Zhu M, Appleyard SM, Wayman GA, Harding JW (2011) Facilitation of hippocampal synaptogenesis and spatial memory by C-terminal truncated Nle1-angiotensin IV analogs. J Pharmacol Exp Ther 339(1):35-44

73. Warburton EC, Brown MW (2015) Neural circuitry for rat recognition memory. Behav Brain Res 285:131-139
74. Krapivinsky G et al (2003) The NMDA receptor is coupled to the ERK pathway by a direct interaction between NR2B and RasGRF1. Neuron 40(4):775-784

75. Caccamo A, Majumder S, Richardson A, Strong R, Oddo S (2010) Molecular interplay between mammalian target of rapamycin (mTOR), amyloid- $\beta$, and tau effects on cognitive impairments. J Biol Chem 285(17):13107-13120

76. Ittner LM et al (2010) Dendritic function of tau mediates amyloid- $\beta$ toxicity in Alzheimer's disease mouse models. Cell 142(3):387-397

77. Zhang Y et al (2010) Genetic reduction of striatal-enriched tyrosine phosphatase (STEP) reverses cognitive and cellular deficits in an Alzheimer's disease mouse model. Proc Natl Acad Sci 107(44):19014-19019

78. Shaftel SS, Griffin WST, O'Banion MK (2008) The role of interleukin-1 in neuroinflammation and Alzheimer disease: an evolving perspective. J Neuroinflammation 5(1):7

79. Matsumoto Y, Yoshida M, Watanabe S, Yamamoto T (2001) Involvement of cholinergic and glutamatergic functions in working memory impairment induced by interleukin- $1 \beta$ in rats. Eur J Pharmacol 430(2):283-288

80. Rachal Pugh C, Fleshner M, Watkins LR, Maier SF, Rudy JW (2001) The immune system and memory consolidation: a role for the cytokine IL-1 $\beta$. Neurosci Biobehav Rev 25(1):29-41

81. Liu M, Shi P, Sumners C (2016) Direct anti-inflammatory effects of angiotensin-(1-7) on microglia. J Neurochem 136(1):163-171

82. Labandeira-Garcia JL, Rodríguez-Perez AI, Garrido-Gil P, Rodriguez-Pallares J, Lanciego JL, Guerra MJ (2017) Brain reninangiotensin system and microglial polarization: implications for aging and neurodegeneration. Front Aging Neurosci 9:129

83. Jimenez $\mathrm{S}$ et al (2008) Inflammatory response in the hippocampus of PS1M146L/APP751SL mouse model of Alzheimer's disease: age-dependent switch in the microglial phenotype from alternative to classic. J Neurosci 28(45):11650-11661

84. Solito E, Sastre M (2012) Microglia function in Alzheimer's disease. Front Pharmacol 3:14

85. Love S, Miners JS (2016) Cerebral hypoperfusion and the energy deficit in Alzheimer's disease. Brain Pathol 26(5):607-617

86. Hajjar I et al (2010) Renin angiotensin system gene polymorphisms modify angiotensin-converting enzyme inhibitors' effect on cognitive function: the Health, Aging and Body Composition Study. J Am Geriatr Soc 58(6): 1035-1042

87. Hajjar I, Levey A (2015) Association between angiotensin receptor blockers and longitudinal decline in tau in mild cognitive impairment. JAMA Neurol 72(9):1069-1070

88. Sandebring A, Welander H, Winblad B, Graff C, Tjernberg LO (2013) The pathogenic A $\beta 43$ is enriched in familial and sporadic Alzheimer disease. PLoS One 8(2): e55847

89. Liu $\mathrm{S}$ et al (2014) Conversion of $\mathrm{A} \beta 43$ to $\mathrm{A} \beta 40$ by the successive action of angiotensin-converting enzyme 2 and angiotensinconverting enzyme. J Neurosci Res 92(9):1178-1186

90. Fischer M, Baessler A, Schunkert H (2002) Renin angiotensin system and gender differences in the cardiovascular system. Cardiovasc Res 53(3):672-677

91. Sandberg K, Ji H (2003) Sex and the renin angiotensin system: implications for gender differences in the progression of kidney disease. Adv Ren Replace Ther 10(1):15-23

92. Komukai K, Mochizuki S, Yoshimura M (2010) Gender and the renin-angiotensin-aldosterone system. Fundam Clin Pharmacol 24(6):687-698

Publisher's Note Springer Nature remains neutral with regard to jurisdictional claims in published maps and institutional affiliations. 